Article

\title{
Electrodeposition of NiSn-rGO Composite Coatings from Deep Eutectic Solvents and Their Physicochemical Characterization
}

\author{
Sabrina Patricia Rosoiu ${ }^{1}$, Aida Ghiulnare Pantazi ${ }^{1}$, Aurora Petica ${ }^{1}$, Anca Cojocaru ${ }^{1,2} \mathbb{D}$, \\ Stefania Costovici ${ }^{1}$, Caterina Zanella ${ }^{3}\left(\mathbb{D}\right.$, Teodor Visan ${ }^{1,2}$, Liana Anicai ${ }^{1, * D}$ and \\ Marius Enachescu 1,4 (D) \\ 1 Center for Surface Science and Nanotechnology, University Politehnica of Bucharest, Splaiul Independentei \\ 313, 060042 Bucharest, Romania; sabrina.rosoiu@cssnt-upb.ro (S.P.R.); aida.pantazi@cssnt-upb.ro (A.G.P.); \\ aura_p25@yahoo.com (A.P.); anca.cojocaru@chimie.upb.ro (A.C.); stefania.costovici@cssnt-upb.ro (S.C.); \\ t_visan@chim.upb.ro (T.V.); marius.enachescu@cssnt-upb.ro (M.E.) \\ 2 Department of Inorganic Chemistry, Physical Chemistry and Electrochemistry, Faculty of Applied Chemistry \\ and Materials Science, University Politehnica of Bucharest, Calea Grivitei 132, 010737 Bucharest, Romania \\ 3 Department of Materials and Manufacturing, School of Engineering, Jönköping University, Gjuterigatan 5, \\ 55318 Jönköping, Sweden; caterina.zanella@ju.se \\ 4 Academy of Romanian Scientists, Splaiul Independentei 54, 050094 Bucharest, Romania \\ * Correspondence: liana.anicai@cssnt-upb.ro
}

Received: 8 September 2020; Accepted: 29 October 2020; Published: 30 October 2020

\begin{abstract}
The present work describes, for the first time, the electrodeposition of NiSn alloy/reduced graphene oxide composite coatings (NiSn-rGO) obtained under pulse current electrodeposition conditions from deep eutectic solvents (choline chloride: ethylene glycol eutectic mixtures) containing well-dispersed GO nanosheets. The successful incorporation of the carbon-based material into the metallic matrix has been confirmed by Raman spectroscopy and cross-section scanning electron microscopy (SEM). A decrease in the crystallite size of the coating was evidenced when graphene oxide was added to the electrolyte. Additionally, the topography and the electrical properties of the materials were investigated by atomic force microscopy (AFM). The corrosion behavior in $0.5 \mathrm{M}$ $\mathrm{NaCl}$ solution was analyzed through potentiodynamic polarization and electrochemical impedance spectroscopy methods for different immersion periods, up to $336 \mathrm{~h}$, showing a slightly better corrosion performance as compared to pure NiSn alloy.
\end{abstract}

Keywords: electrodeposition; NiSn-rGO composite coating; deep eutectic solvent; direct current plating; pulse current plating; corrosion

\section{Introduction}

In recent years, graphene and its derivatives (graphene oxide and reduced graphene oxide) have attracted considerable attention, since they have found potential applications in diverse areas such as electronics, energy storage, sensors, light processing, medical and industrial processes [1].

Graphene $(\mathrm{G})$, consisting of a single layer of graphite where the $\mathrm{sp}^{2}$ carbon bonded atoms are hexagonally arranged, attracted increased attention due to its unique optical, mechanical, conductive and electronic properties, chemical inertness and impermeability to ion diffusion. However, G exhibits a poor dispersibility in solvents [2-4], thus limiting wide use in many fields.

In spite of the promising potential $\mathrm{G}$ may provide in the anti-corrosion field, mainly because of its hydrophobic nature, it has been shown that pure $G$ coatings are highly susceptible to surface defects upon extended exposure to corrosive media leading to localized corrosion of metal substrate $[3,5]$. 
To overcome these disadvantages, the use of another derivative, graphene oxide (GO), has been considered. Graphene oxide (GO) is the oxidized form of graphene where the plane of carbon atoms is decorated with oxygen containing groups such as epoxide, hydroxyl, carbonyl and carboxyl. Due to the presence of these functional groups, GO is hydrophilic and forms stable dispersions in aqueous and non-aqueous media. In addition, GO exhibits higher chemical activity and the presence of the attached groups and lattice defects inhibit its electrical conductivity, making GO electrically resistive [6,7]. GO can be treated using various methods to synthesize reduced graphene oxide (rGO) in order to minimize the number of oxygen groups and achieve properties closer to those of pristine graphene. These structure changes also provide the partial recovery of electrical conductivity. rGO can be obtained by thermal [6], chemical [8] or electrochemical $[9,10]$ procedures.

A large number of papers reported in recent years investigated the fabrication of metallic composite coatings with incorporated graphene-related materials. Their presence in different metallic matrices facilitated in increase of the corrosion resistance, microhardness and wear resistance [3].

Several preparation methods can be used to obtain the metallic matrix composite coatings, including chemical vapor deposition, cold spray, electroless deposition and electrodeposition. Among them, electrodeposition is widely used because it allows for obtaining of a large range of functional and protective metal or alloy composite coatings with lower cost, high deposition rates and microstructure control. When GO is used during the electrodeposition process, rGO is formed at the cathode surface [4,9-12].

$\mathrm{Ni}$ matrix composite coatings reinforced with graphene-related materials, including Ni-graphene (Ni-G), Ni-graphene oxide (Ni-GO) and Ni-reduced graphene oxide (Ni-rGO) on different metal substrates, were reported in [13-25], using aqueous electrolytes. The incorporation of graphene particles into the Ni matrix was found to change the surface morphology to a fine-grained deposit and reduced the crystallite size. Moreover, the thermal conductivity, hardness and corrosion resistance were improved. Ding et al. [18] obtained self-cleaning Ni-graphene composite with a hierarchical micro-nano structure of nickel and graphene particles; additionally, the coated surface exhibited super-hydrophobicity. In a series of works, Singh et al. $[19,22,23]$ established a pulse-current deposition route to directly synthesize $\mathrm{Ni}$ composites with GO, GO functionalized with octadecyl amine or with both GO and SiC particles. The addition of GO to the Ni matrix reduced the water contact angle [19]. The diminishing of the friction coefficient and superior tribological properties by enhancing the elastic modulus were attributed to the synergistic effects of SiC and GO [22]. Functionalization with octadecyl amine led to Ni composites converted from hydrophilic to hydrophobic [23]. Additionally, the functionalization improved the structural and thermal stability, hardness and, in turn, improved the frictional and wear resistance of the composite coating. These results open up new opportunities for self-lubricating coatings in automobile applications and other mechanical assemblies. The improvement of surface anti-friction properties and wear resistance for aluminum alloys coated with Ni-G and Ni-GO composites is also the subject of recent studies [24,25]. Sn-graphene composite coatings on mild steel have been investigated by Berlia et al. [26], using acidic $\mathrm{SnCl}_{2}$ aqueous electrolytes containing graphene produced by the electrochemical exfoliation of graphite. Incorporation of $G$ into the growing $\mathrm{Sn}$ metal matrix during the electrodeposition led to a change in surface morphology and a decrease in grain size. Corrosion current and corrosion rate values were lower, and the impedance diagrams indicated a reduction in the double layer capacitance. Similar behavior was found during the electrodeposition of SnZn-graphene oxide (SnZn-GO) composites on a mild steel substrate [18]. Graphene oxide was prepared by oxidation of graphite in a plating bath containing $\mathrm{SnSO}_{4}$ and $\mathrm{ZnSO}_{4}$. The smoothness and the compactness of the coatings increased with the content of GO, but the incorporation of GO did not cause any significant change in the crystallite size of either Sn or Zn phases. Better anticorrosive behavior as well as a decrease in the double layer capacitance were also observed for SnZn-GO composites.

In spite of the promising characteristics that the metal and alloy composite coatings reinforced with graphene-related materials may provide, their electrochemical preparation using aqueous solutions 
sometimes suffers from some limitations, related to the occurrence of hydrogen evolution as a secondary reaction affecting the cathodic efficiency, the narrow electrochemical window and sometimes the complexity and toxicity of the electrolyte composition, requiring the use of additives.

To address these shortcomings, ionic liquids (ILs) and deep eutectic solvents (DESs) have been used for the electrodeposition of a large range of metals and alloys, including their composites with various carbon-based nanomaterials $[27,28]$. In the recent decades, DESs, comprising a mixture of a quaternary ammonium salt with hydrogen bond donors, such as amides, carboxylic acids or alcohols, have especially attracted the attention of researchers. They are potentially recyclable, biodegradable and with cause no harm to on human health, so they may represent a "green alternative" as electrolytes for metal and alloy electrodeposition, as well as for various other chemical processes. In addition, these electrolytic media are characterized by a good air and water stability without requiring any additional manipulation processes [29,30].

Li et al. [4] reported the successful electrodeposition of zinc-graphene oxide (Zn-GO) composite coatings by applying pulse electrodeposition in choline chloride $(\mathrm{ChCl}) /$ urea based DESs. The use of this eutectic mixture facilitated a good dispersion stability of the GO sheets with no need of supplementary additives. Based on X-ray Photoelectron Spectroscopy (XPS) investigations it has been shown that during the electrodeposition process, part of the oxygen functional groups were removed and the GO was partially reduced. The Zn-GO composite coatings were found to exhibit higher stability and better corrosion resistance than the pure $\mathrm{Zn}$ coating. Furthermore, the corrosion resistance of $\mathrm{Zn}-\mathrm{GO}$ composite coatings increased as the GO content in the electrolyte was higher.

Brandao et al. [31] electrodeposited Sn composite coatings using a choline chlorideethylene glycol-based DES, also known as ethaline, involving different carbon nanomaterials. Among these, the behavior of Sn-reduced graphene oxide (Sn-rGO) composite was also investigated. Interestingly, both cathodic and anodic voltammetric peaks for the Sn-rGO composite had peak currents lower than for pristine Sn coating. Using chronoamperograms, a strong effect of the presence of the carbon materials was observed, in particular when $0.5 \mathrm{~g} / \mathrm{L} \mathrm{rGO}$ was added, and this was evidence of the rGO incorporation into the Sn matrix. This composite also presented more roughness compared to the pure Sn coating, but lower electrical conductivity, explained by the amorphous carbon present in the deposit. Corrosion studies showed that the presence of rGO involved a higher charge transfer resistance than the one exhibited by the bare Sn coating, which decreased with prolonged immersion.

Nickel-tin alloys have a wide range of applications, such as in electrical connectors, printed circuits boards and batteries. Additionally, they represent an alternative to chromium decoration due to their anticorrosive properties and have the advantage of being non-allergenic compared to the pure $\mathrm{Ni}$ metal [32]. Besides aqueous solutions, melts or traditional ionic liquids, NiSn alloy coatings were electrodeposited on various substrates [33-37] using electrolytes based on DESs, which are considered as a novel and highly promising kind of ionic liquids analog.

However, the incorporation of graphene oxide into the metallic matrix of NiSn alloy has been studied in a single published paper [38]. Nano-crystalline NiSn-GO composite coatings were electrodeposited under direct current conditions on mild steel from an aqueous solution containing nickel and tin chlorides. The morphological and structural property studies revealed the presence of $\mathrm{Sn}$, $\mathrm{Ni}_{3} \mathrm{Sn}_{4}, \mathrm{Ni}_{3} \mathrm{Sn}_{2}$ and $\mathrm{Ni}_{3} \mathrm{Sn}$ intermetallic phases in the matrix. The addition of GO led to a considerable decrease in the grain size in the Sn-rich phase. A corrosion study by Tafel curves and impedance diagrams indicated the formation of passive $\mathrm{NiO}$ and $\mathrm{SnO}$ phases on the surface and a higher content of graphene oxide was responsible for the increase in the corrosion resistance compared to the bare NiSn alloy.

Considering all the studies discussed above, the present study reports the electrodeposition and characterization of nickel-tin alloy with reduced graphene oxide as a composite synthesized under pulse current conditions from a choline chloride:ethylene glycol mixture (1:2 mole ratio) as a deep eutectic solvent (DES). Dispersed ammonia functionalized GO was involved to prepare the electrolytes. 
During the electrochemical reduction process, GO was reduced to rGO and incorporated within the NiSn alloy matrix.

The electrodeposition of NiSn alloys from choline chloride: ethylene glycol eutectic mixtures under direct current and pulse current conditions has been previously reported by our group in [37]. It was noticed that the NiSn alloy coatings prepared under pulse current electrodeposition conditions showed an improvement in the mechanical properties as compared to the ones prepared involving direct current.

In the present study, the influence of the pulse current electrodeposition parameters on the preparation of the NiSn-rGO composite materials wasinvestigated. The resulting NiSn-rGO composite coatings were analyzed by SEM, X-ray diffraction (XRD) and Raman spectroscopy. The roughness and conductivity of the coatings were evaluated by atomic force microscopy (AFM) and their anticorrosive properties were investigated by both electrochemical impedance spectroscopy (EIS) and Tafel potentiodynamic polarization after different durations of immersion in $0.5 \mathrm{M} \mathrm{NaCl}$ solution. To the best of our knowledge, this is the first investigation reporting the electrodeposition and characterization of NiSn-rGO composite coatings involving DESs.

\section{Materials and Methods}

\subsection{Chemicals and Electrolyte Preparation}

For the preparation of the involved choline chloride-ethylene glycol eutectic mixture (denoted as ILEG), choline chloride ( $\mathrm{ChCl}$ ) (Emprove Merck, Darmstadt, Germany 98\%) and ethylene glycol (EG) (Silal Trading Bucharest, Bucharest, Romania 99\%) were mixed in a 1:2 molar ratio and heated at $80 \pm 5{ }^{\circ} \mathrm{C}$ under gentle magnetic stirring $(200 \mathrm{rpm})$ until a colorless liquid was formed. To this DES, the corresponding amounts of tin chloride $\left(\mathrm{SnCl}_{2} \cdot 2 \mathrm{H}_{2} \mathrm{O}\right)$ (Actros Thermo Fisher Scientific, Geel, Belgium, 97\%) and nickel chloride $\left(\mathrm{NiCl}_{2} \cdot 6 \mathrm{H}_{2} \mathrm{O}\right)$ (Lach-Ner, Neratowitz, Czech Republic, 99\%) salts were added at $80 \pm 5^{\circ} \mathrm{C}$ and the liquid was stirred $(200 \mathrm{rpm})$ until a homogenous green solution was formed. For the synthesis of the composite material, $0.1 \mathrm{~g} / \mathrm{L}$ of graphene oxide ammonia functionalized $(1 \mathrm{mg} / \mathrm{mL} \mathrm{GO}$, dispersion in water) (Sigma-Aldrich, Darmstadt, Germany) were added to this solution (50 mL) and ultrasound stirred at $67 \mathrm{~W}$ for $90 \mathrm{~s}$, using a SONICS Vibra-Cell high intensity ultrasonic processor probe (model VCx500; SONICS\&MATERIALS, Inc., Newtown, CT, USA), until a homogeneous and stable dispersion was obtained (unaffected dispersion stability for at least $48 \mathrm{~h}$ ). All the reagents were used as received.

\subsection{Electrodeposition Experiments}

In order to investigate the composite electrodeposition process, $0.5 \mathrm{M} \mathrm{SnCl}_{2} 2 \mathrm{H}_{2} \mathrm{O}$ and $0.5 \mathrm{M}$ $\mathrm{NiCl}_{2} \cdot 6 \mathrm{H}_{2} \mathrm{O}$ as metal precursors and $0.1 \mathrm{~g} / \mathrm{L} \mathrm{GO}$ were added to the ILEG eutectic mixture. For the electrodeposition of NiSn-alloys, the electrolyte contained the same amount of the metallic salts as in the case of the composite material. All prepared media were in liquid state at room temperature.

The coatings were obtained by electrodeposition in galvanostatic mode, using a pulse reverse power supply (pe86CB3HE, Plating Electronic $\mathrm{GmbH}$, Sexau, Germany). The electrodeposition process was performed in an open system at $75 \pm 5^{\circ} \mathrm{C}$, under ultrasound external stirring $(2.9 \mathrm{~W} / \mathrm{L})$ in order to preserve the dispersion of the carbon-based material. A two-electrode cell configuration was employed, where a copper $(\mathrm{Cu})$ sheet, with a thickness of $0.2 \mathrm{~mm}$ and a surface area of $0.75 \mathrm{~cm}^{2}$, and a platinized titanium mesh, were used vertically as cathode and anode, respectively, as shown in Figure 1 . The $\mathrm{Cu}$ sheets were cleaned with acetone, rinsed with deionized water and immersed in $\mathrm{HNO}_{3}: \mathrm{H}_{2} \mathrm{O}$ solution (1:1 vol. \%) for $30 \mathrm{~s}$ at room temperature prior to the electrodeposition, followed by rinsing with deionized water and air drying. 


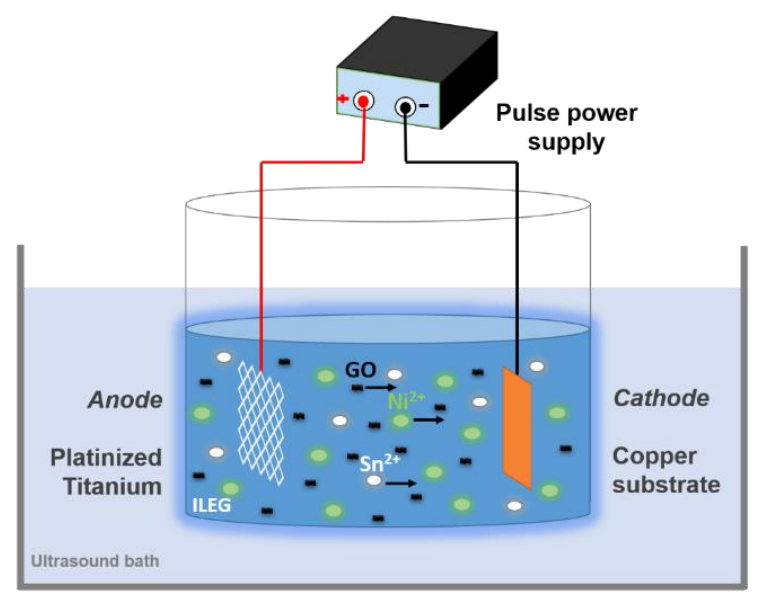

Figure 1. A schematic diagram of the pulse electrodeposition system used in this study.

For the electrodeposition of the composite coatings, the $\mathrm{T}_{\mathrm{ON}}$ time was set at $500 \mathrm{~ms}$, while the $\mathrm{T}_{\text {OFF }}$ time was varied: 250,500 and $1000 \mathrm{~ms}$ at a constant peak current density of $20 \mathrm{~mA} / \mathrm{cm}^{2}$.

After the optimization of the $\mathrm{T}_{\mathrm{OFF}}$ time, both pure NiSn alloys and composite coatings were prepared at $75 \pm 5{ }^{\circ} \mathrm{C}$ by electrodeposition under pulse current and ultrasound external stirring ( $2.9 \mathrm{~W} / \mathrm{L})$ at different current peak densities: 10, 15, 20 and $25 \mathrm{~mA} / \mathrm{cm}^{2}$. The deposition time was selected according the pulse parameters in order to obtain the same thickness. The film thickness of the optimized bare NiSn alloy and composite coatings was obtained by gravimetric analysis of the deposit: $10 \pm 1 \mu \mathrm{m}$ (current efficiency: $65 \pm 2.5 \%$ ). After the electrodeposition, the coatings were cleaned with hot deionized water and acetone and air dried.

\subsection{Cyclic Voltammetry and Corrosion Experiments}

In order to get more information on the cathodic processes during the alloy composite deposition, cyclic voltammetry investigations were performed involving ILEG-based electrolytes containing $\mathrm{SnCl}_{2} \cdot 2 \mathrm{H}_{2} \mathrm{O}, \mathrm{NiCl}_{2} \cdot 6 \mathrm{H}_{2} \mathrm{O}$ and GO, as shown in Table 1 .

Table 1. The composition of electrolytes for cyclic voltammetry investigations.

\begin{tabular}{cc}
\hline System Type & Metal Salt/GO Content \\
\hline ILEG-GO & ILEG $+0.1 \mathrm{~g} / \mathrm{L} \mathrm{GO}$ \\
$\mathrm{Sn}-\mathrm{GO}$ & $\mathrm{ILEG}+0.05 \mathrm{M} \mathrm{SnCl} \mathrm{H}_{2} \cdot 2 \mathrm{H}+0.1 \mathrm{~g} / \mathrm{L} \mathrm{GO}$ \\
$\mathrm{Ni-GO}$ & $\mathrm{ILEG}+0.05 \mathrm{M} \mathrm{NiCl}_{2} \cdot 6 \mathrm{H}_{2} \mathrm{O}+0.1 \mathrm{~g} / \mathrm{L} \mathrm{GO}$ \\
$\mathrm{NiSn}-\mathrm{GO}$ & $\mathrm{ILEG}+0.05 \mathrm{M} \mathrm{SnCl} \mathrm{H}_{2} \cdot 2 \mathrm{H}_{2} \mathrm{O}+0.05 \mathrm{M} \mathrm{NiCl}_{2} \cdot 6 \mathrm{H}_{2} \mathrm{O}+0.1 \mathrm{~g} / \mathrm{L} \mathrm{GO}$ \\
\hline
\end{tabular}

The electrochemical measurements were performed using the PARSTAT 4000 (Ametek, Berwyn, PA, USA) potentiostat controlled with VersaStudio software (2.1 version, Ametek, Berwyn, PA, USA). The cyclic voltammetry experiments were carried out at $75^{\circ} \mathrm{C}$ in stationary conditions, at several scan rates, starting at Open Circuit Potential (OCP) and scanning towards negative potential up to $-1.6 \mathrm{~V}$ and then towards positive potential up to $+1.6 \mathrm{~V}$. A three-electrode system was employed, where glassy carbon (GC, Metrohm, Herisau, Switzerland) with a diameter of $5 \mathrm{~mm}$ was used as working electrode $\left(\mathrm{S}_{\mathrm{WE}}=0.196 \mathrm{~cm}^{2}\right)$, a silver $(\mathrm{Ag})$ wire as quasi-reference electrode and a platinum (Pt) plate (Metrohm, Herisau, Switzerland) as counter electrode. Prior to each measurement, the GC working electrode was polished with $1 \mu \mathrm{m}$ diamond paste (Buehler) followed by $0.3 \mu \mathrm{m}$ alumina suspension solution (Buehler), rinsed with deionized water and air dried.

The corrosion behavior of the electrodeposited composite coatings was assessed by accelerated laboratory tests consisting in continuous immersion in aerated $0.5 \mathrm{M} \mathrm{NaCl}$ solution at $25^{\circ} \mathrm{C}$ for up to $336 \mathrm{~h}$, with intermediary visual examinations. Potentiodynamic polarization curves at a scan 
rate of $5 \mathrm{mV} \mathrm{s}^{-1}$ and electrochemical impedance spectroscopy (EIS) spectra at opencircuit potential using $0.5 \mathrm{M} \mathrm{NaCl}$ solution were recorded against a $\mathrm{Ag} / \mathrm{AgCl}$ reference electrode and Pt plate counter electrode. For both electrochemical investigations, the geometrical surface of the working electrode was $0.63 \mathrm{~cm}^{2}$. The EIS spectra, recorded with $10 \mathrm{mV}$ a.c. voltage within the $0.1-10^{5} \mathrm{~Hz}$ frequency range, werefitted using ZView 2.7 software (Scribner Association Inc, Southern Pines, NC, USA). A minimum of three pieces of each optimized NiSn-alloy and NiSn-rGO composite coating deposited onto a $\mathrm{Cu}$ metallic substrate $(65 \times 25 \mathrm{~mm})$ were tested.

\subsection{Surface Characterization}

The surface morphology and chemical composition of the optimized NiSn alloy and NiSn-rGO composite coatings were studied by scanning electron microscopy (SEM) (Hitachi SU 8230, Hitachi High-Tech Corporation, Tokyo, Japan) equipped with an energy dispersive X-ray detector (EDX, Oxford Instuments, Oxford, UK) and a JEOL JSM-7001F SEM (JEOL, Tokyo, Japan). The structural properties of the prepared coatings were investigated by an X-ray diffractometer (XRD) system (Rigaku SmartLab, Tokyo, Japan) possessing $\mathrm{Cu} \mathrm{K} \alpha$ radiation $(\lambda=0.15406 \mathrm{~nm})$, at room temperature, in the $2 \theta$ range of $5^{\circ}-90^{\circ}$. The crystallite size, $\mathrm{D}$, was determined according to Scherrer's equation:

$$
\mathrm{D}=\frac{K \lambda}{\beta \cos (\theta)}
$$

where $k$ is Scherrer's constant (0.94), $\beta$ the full width at half maximum and $\theta$ the diffraction angle.

The characterization of the carbon-based material and the optimized composite coatings was also performed by Raman spectroscopy at room temperature using the LabRam HR800 system (Horiba, Kyoto, Japan). The samples were exposed to a green laser of a $532 \mathrm{~nm}$ wavelength $(0.85 \mathrm{~mW})$ for $100 \mathrm{~s}$ and the specimen-emitted signal was dispersed onto the charge coupled device (CCD) detector (Horiba, Kyoto, Japan) using a 600 lines/mm grating.

Additionally, the morphological and electrical properties of the NiSn alloys and NiSn-rGO composite coatings were carried out by atomic force microscopy (AFM) in an NT-MDT Solver NEXT system (NT-MDT Spectrum Instruments, Zelenograd, Russia) operating in contact mode. The AFM measurements were performed using bare and Pt-coated cone-shaped tips from monocrystalline silicon, mounted on cantilevers with $12 \mathrm{~N} / \mathrm{m}$ and $0.3 \mathrm{~N} / \mathrm{m}$ spring constants, with areas of $10 \times 10 \mu \mathrm{m}^{2}$ and $3 \times 3 \mathrm{~mm}^{2}$, respectively. The height, lateral force and current signals were acquired simultaneously.

The root mean square roughness $\left(R_{R M S}\right)$ and the roughness average $(R a)$ parameters were calculated from the acquired topographic images using image processing software. RMS is defined as:

$$
R_{R M S}=\sum_{i=1}^{N}\left[\frac{\left(h_{i}-\bar{h}\right)^{2}}{N}\right]^{1 / 2}
$$

where $h_{i}$ represents the height value at each data point, $\bar{h}$ represents the profile mean value of the surface, and $\mathrm{N}$ represents the number of data points in the analyzed profile. The average roughness, $\mathrm{Ra}$, represents the arithmetic average of the deviations in height from the profile mean value:

$$
R_{a}=\frac{1}{N} \sum_{i=1}^{N}\left|h_{i}-\bar{h}\right|
$$


The root mean square electrical current $\left(I_{R M S}\right)$ and the average electrical current $\left(I_{a}\right)$ parameters were calculated from the acquired electrical conductivity distribution images via image processing software, using the Equations (4) and (5):

$$
\begin{gathered}
I_{R M S}=\sum_{i=1}^{N}\left[\frac{\left(c_{i}-\bar{c}\right)^{2}}{N}\right]^{1 / 2} \\
I a=\frac{1}{N} \sum_{i=1}^{N}\left|c_{i}-\bar{c}\right|
\end{gathered}
$$

where $c_{i}$ represents the electrical current value at each data point, $\bar{c}$ represents the electrical current mean value and $N$ represents the number of analyzed data points.

\section{Results and Discussion}

\subsection{Cyclic Voltammetry Experiments}

The cyclic voltammograms of the electrolytes containing GO, Sn or/and Ni ionic species (Table 1), presented in Figure 2a,b, were recorded on a GC working electrode at $75^{\circ} \mathrm{C}$ using a $20 \mathrm{mV} / \mathrm{s} \mathrm{scan} \mathrm{rate.}$

Voltammetric experiments were mainly carried out by scanning at first to negative potentials. As shown in Figure 2a, in the case of ILEG solvent with $0.1 \mathrm{~g} / \mathrm{L} \mathrm{GO}$ (ILEG-GO system), no electrochemical process is observed up to a $-1.1 \mathrm{~V}$ potential, where the onset of the cathodic current corresponds to the beginning of GO sheets reduction [39]. The peak potential is at around $-1.4 \mathrm{~V}$ in the first cycle but is shifted to $-1.3 \mathrm{~V}$ in the following cycles. After this peak (which is rather a plateau), the cathodic current began to continuously increase due to reduction of cholinium cations from ILEG as a background electrolyte. On the anodic branch of the cyclic voltammetry $(\mathrm{CV})$ curve, only the oxidation of chloride complex anions (due to hydrogen bonds between $\mathrm{Cl}^{-}$and EG molecules) is observed, followed by a corresponding reduction peak on the return scan. This part is similar to that for the ILEG background electrolyte [40]. The increase in both reduction current and oxidation current by multicycling is monotonous.

In Figure $2 b$, the voltammogram of the Sn-GO system clearly evidenced a cathodic peak at about $-0.45 \mathrm{~V}$, corresponding to the reduction of the $\mathrm{Sn}^{2+}$ ions to $\mathrm{Sn}^{0}$, and two anodic peaks, first corresponding to the stripping of metallic deposits and the occurrence of $\mathrm{Sn}^{2+}$ (at $-0.27 \mathrm{~V}$ ) and their further oxidation to $\mathrm{Sn}^{4+}$ ions (at $\sim 1 \mathrm{~V}$ ), in agreement with [41]. The addition of GO increases the current of the peak, corresponding to the oxidation of $\mathrm{Sn}^{2+}$ to $\mathrm{Sn}^{4+}$ (not shown here). In the case of the voltammogram corresponding to the Ni-GO system, a reduction peak at around $-0.72 \mathrm{~V}$ was evidenced on the cathodic scan, which may be assigned to the deposition of pure Ni metal. Regarding the anodic process, one can see an oxidation peak at about $0.71 \mathrm{~V}$, assigned to $\mathrm{Ni}^{2+}$ formation by $\mathrm{Ni}$ dissolution.

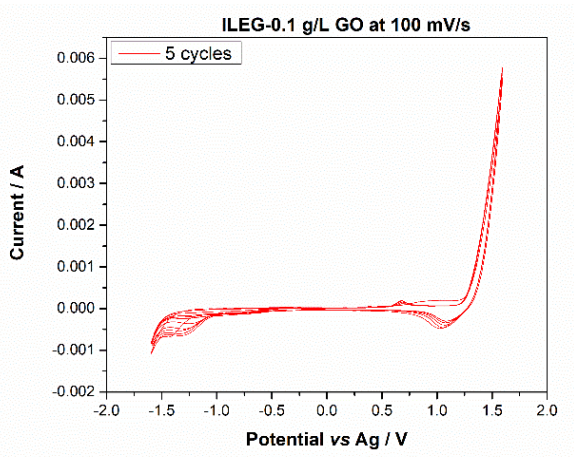

(a)

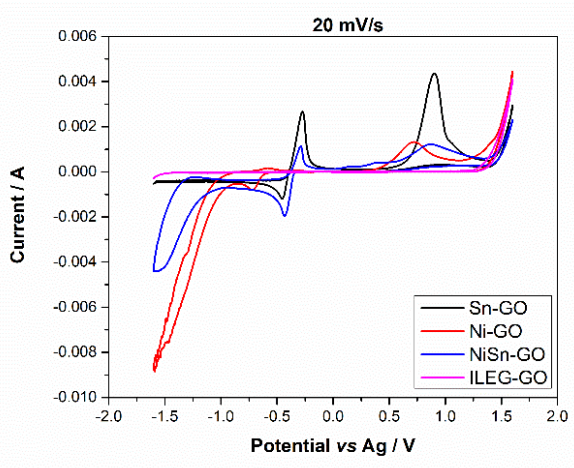

(b)

Figure 2. Cont. 


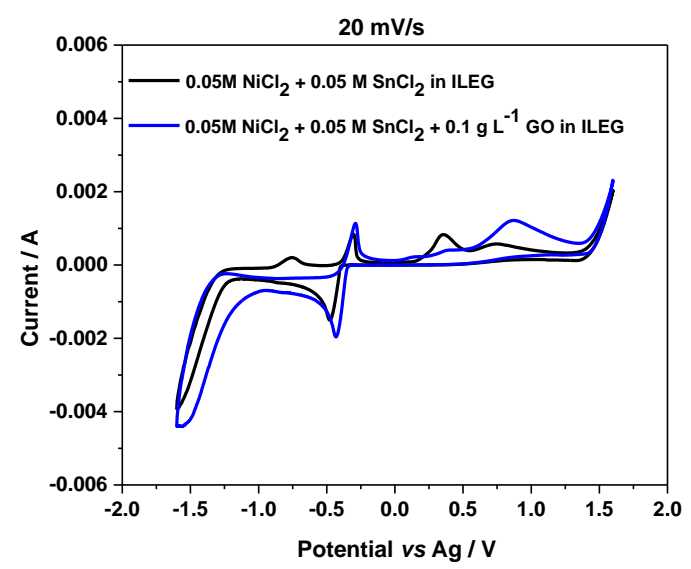

(c)

Figure 2. Cyclic voltammograms (CVs) on a glassy carbon (GC) electrode at $75^{\circ} \mathrm{C}$ for: (a) multiple cycles for ILEG-GO electrolyte system at $100 \mathrm{mV} / \mathrm{s}$; (b) the first cycle for Sn-GO, Ni-GO, NiSn-GO and ILEG-GO electrolyte systems and (c) comparative CVs for NiSn systems in the absence and in the presence of $\mathrm{GO}$, at $20 \mathrm{mV} / \mathrm{s}$.

When all the metallic ionic species are present in the electrolyte (the case for the CV of the NiSn-GO system), only a single cathodic peak at $-0.43 \mathrm{~V}$ is observed, which may be assigned to a direct co-deposition of both metals (although the $\mathrm{Ni}^{2+} / \mathrm{Ni}$ process alone was $-0.72 \mathrm{~V}$, more negative) with NiSn alloy formation. As Figure 2c shows, the presence of GO in the electrolyte does not induce a significant displacement of the cathodic peak assigned to the alloy electrodeposition as previously reported in [35]. Furthermore, the cathodic peak current for the NiSn system containing GO is slightly higher than that without GO. On the anodic branch of the $\mathrm{CV}$, three oxidation peaks are evidenced, which may be ascribed to tin dissolution, to nickel dissolution and to the oxidation of $\mathrm{Sn}^{2+}$ to $\mathrm{Sn}^{4+}$. An increase in the current of the peak assigned to the oxidation of $\mathrm{Sn}^{2+}$ to $\mathrm{Sn}^{4+}$ was also observed.

\subsection{Pulse Current Electrodeposition of NiSn-rGO Composite and Surface Characterization}

The influence of the pulse current parameters on the incorporation of the carbonic material into the metallic matrix was investigated. In order to keep the graphene oxide content in the electrolyte constant, ultrasound stirring was used during the pulse electrodeposition process. The $\mathrm{T}_{\mathrm{ON}}$ time was kept constant, while the $\mathrm{T}_{\mathrm{OFF}}$ time varied. The operating parameters set during the electrodeposition of the composite material are presented in Table 2.

Table 2. Operating parameters for the electrodeposition of NiSn-rGO from ILEG, $t=30$ min and a constant peak current density.

\begin{tabular}{cccc}
\hline Electrolysis Parameter & NiSn-rGO-P1 & NiSn-rGO-P2 & NiSn-rGO-P3 \\
\hline \multirow{2}{*}{ On- and off-time duration of the pulse } & $\mathrm{T}_{\mathrm{ON}}=500 \mathrm{~ms}$ & $\mathrm{~T}_{\mathrm{ON}}=500 \mathrm{~ms}$ & $\mathrm{~T}_{\mathrm{ON}}=500 \mathrm{~ms}$ \\
Frequency $(\mathrm{f})$ & $\mathrm{T}_{\mathrm{OFF}}=250 \mathrm{~ms}$ & $\mathrm{~T}_{\mathrm{OFF}}=500 \mathrm{~ms}$ & $\mathrm{~T}_{\mathrm{OFF}}=1000 \mathrm{~ms}$ \\
Duty cycle $(\theta)$ & $\mathrm{f}=1.33 \mathrm{~Hz}$ & $\mathrm{f}=1 \mathrm{~Hz}$ & $\mathrm{f}=0.67 \mathrm{~Hz}$ \\
Peak current density $\left(\mathrm{i}_{\mathrm{p}}\right)$ & $\theta=0.67$ & $\theta=0.5$ & $\theta=0.33$ \\
& $\mathrm{i}_{\mathrm{p}}=20 \mathrm{~mA} / \mathrm{cm}^{2}$ & $\mathrm{i}_{\mathrm{p}}=20 \mathrm{~mA} / \mathrm{cm}^{2}$ & $\mathrm{i}_{\mathrm{p}}=20 \mathrm{~mA} / \mathrm{cm}^{2}$ \\
\hline
\end{tabular}

$\mathrm{T}_{\mathrm{ON}}$ and $\mathrm{T}_{\mathrm{OFF}}$ are the on and off time durations of the pulse.

As can be observed from the SEM micrographs shown in Figure 3, the increase in the $\mathrm{T}_{\mathrm{OFF}}$ time seems to lead to a better incorporation of the carbon-based material, since the chance of the graphene sheets reaching the cathode is increased. NiSn-rGO-P3 showed a better distribution of the rGO sheets on the surface of the coating and a change in the morphology. 


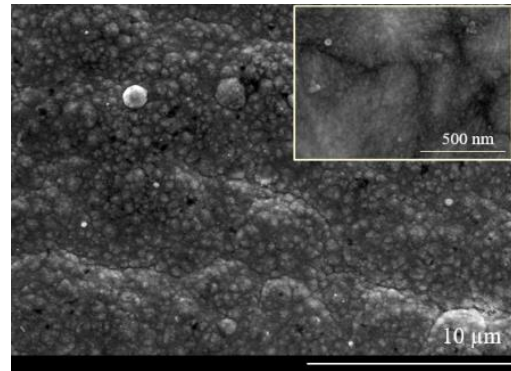

(a)

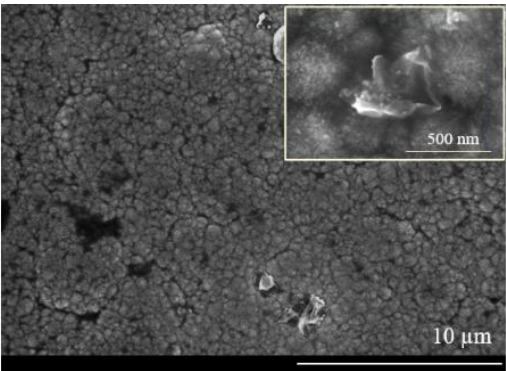

(b)

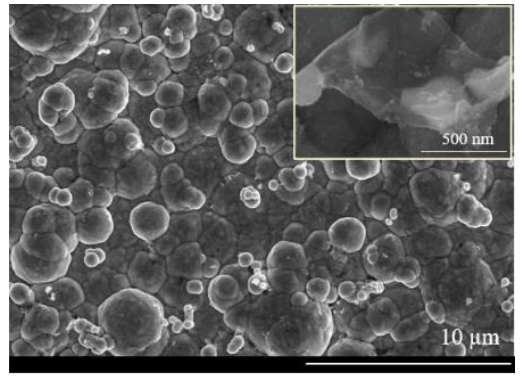

(c)

Figure 3. SEM micrographs of samples: (a) NiSn-rGO-P1, (b) NiSn-rGO-P2 and (c) NiSn-rGO-P3.

Considering the optimal pulse plating conditions, $\mathrm{T}_{\mathrm{ON}}=500 \mathrm{~ms}$ and $\mathrm{T}_{\mathrm{OFF}}=1000 \mathrm{~ms}$, NiSn alloys and NiSn-rGO composite coatings were prepared at several values of the peak current density, as presented in Table 3. Figures 4 and 5 show the SEM micrographs of NiSn alloys and NiSn-rGO composite coatings prepared by electrodeposition at different current peak densities.

Table 3. Operating parameters for the electrodeposition of NiSn-alloy and NiSn-rGO from ILEG at various peak current densities.

\begin{tabular}{cccccc}
\hline Coatings & $\begin{array}{c}\text { Electrodeposition } \\
\text { Parameters }\end{array}$ & & Peak Current Density & \\
& $\mathrm{T}_{\mathrm{ON}}=500 \mathrm{~ms}$ & NiSn-P3.1 & NiSn-P3.2 & NiSn-P3.3 & NiSn-P3.4 \\
NiSn-alloys & $\mathrm{T}_{\mathrm{OFF}}=1000 \mathrm{~ms}$ & $\mathrm{i}_{\mathrm{p}}=10 \mathrm{~mA} / \mathrm{cm}^{2}$ & $\mathrm{i}_{\mathrm{p}}=15 \mathrm{~mA} / \mathrm{cm}^{2}$ & $\mathrm{i}_{\mathrm{p}}=20 \mathrm{~mA} / \mathrm{cm}^{2}$ & $\mathrm{i}_{\mathrm{p}}=25 \mathrm{~mA} / \mathrm{cm}^{2}$ \\
& $\mathrm{~F}=0.67 \mathrm{~Hz}$ & NiSn-rGO-P3.1 & NiSn-rGO-P3.2 & NiSn-rGO-P3.3 & NiSn-rGO-P3.4 \\
NiSn-rGO & $\theta=0.33$ & $\mathrm{i}_{\mathrm{p}}=10 \mathrm{~mA} / \mathrm{cm}^{2}$ & $\mathrm{i}_{\mathrm{p}}=15 \mathrm{~mA} / \mathrm{cm}^{2}$ & $\mathrm{i}_{\mathrm{p}}=20 \mathrm{~mA} / \mathrm{cm}^{2}$ & $\mathrm{i}_{\mathrm{p}}=25 \mathrm{~mA} / \mathrm{cm}^{2}$ \\
\hline
\end{tabular}

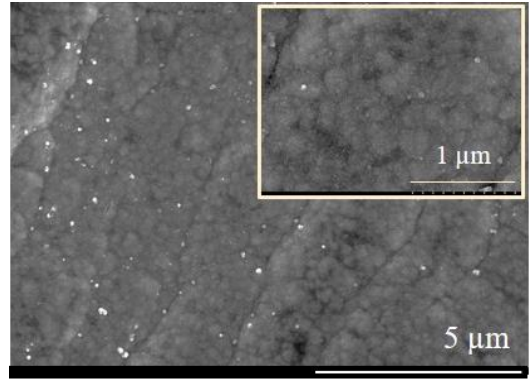

(a)

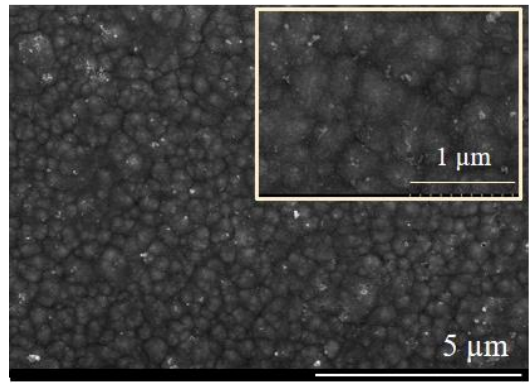

(c)

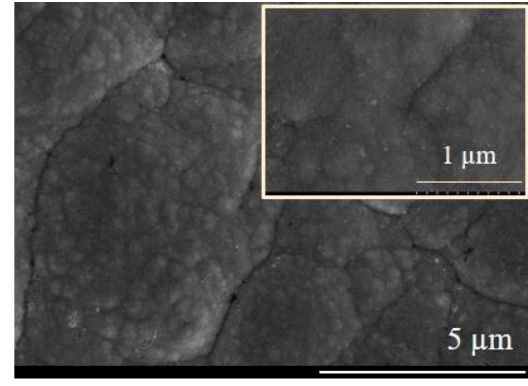

(b)

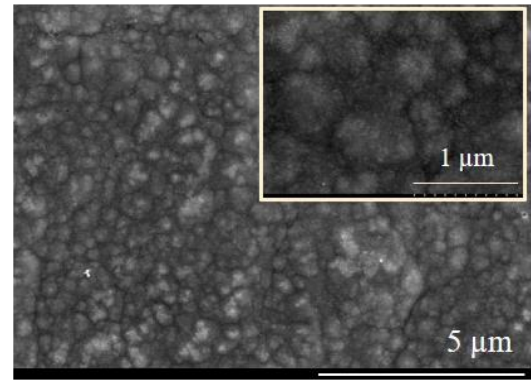

(d)

Figure 4. SEM micrographs of NiSn alloys obtained at different peak current densities: (a) NiSn-P3.1, (b) NiSn-P3.2, (c) NiSn-P3.3 and (d) NiSn-P3.4. 


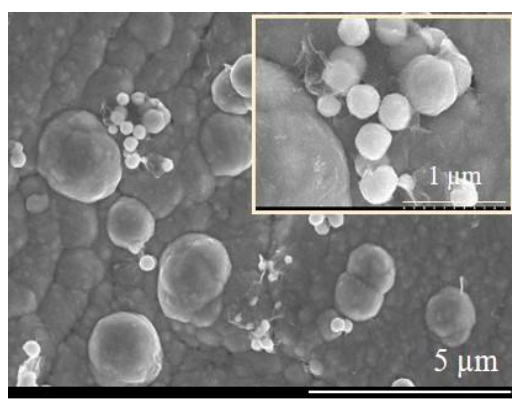

(a)

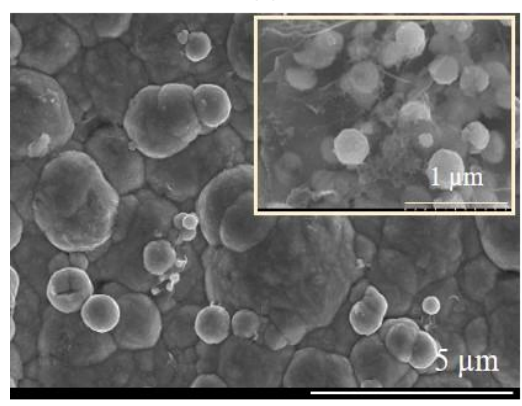

(c)

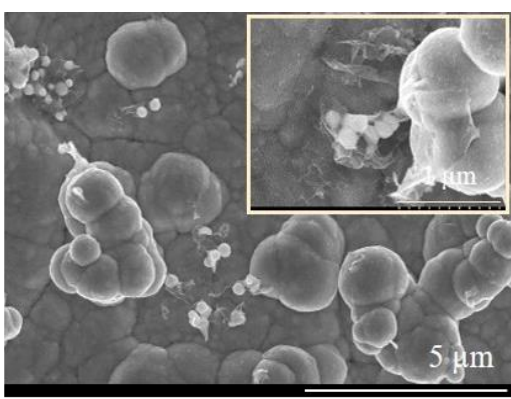

(b)

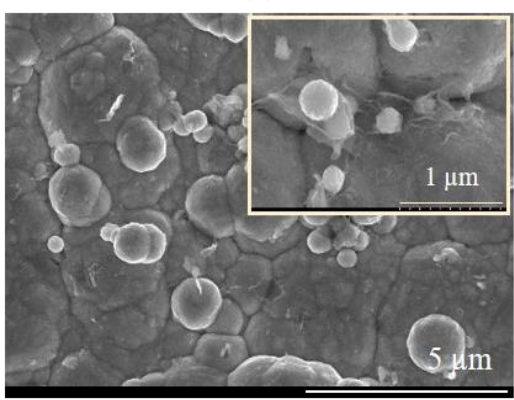

(d)

Figure 5. SEM micrographs of NiSn-rGO obtained at different peak current densities: (a) NiSn-rGO-P3.1, (b) NiSn-rGO-P3.2, (c) NiSn-rGO-P3.3 and (d) NiSn-rGO-P3.4.

The elemental composition of the coatings was determined using the EDX technique. The carbon determined by the EDX analysis is originated not only from the rGO sheets but also from the deep eutectic solvent. The results showed that the composition of the alloys did not change with the peak current density applied. Values of $65.83 \pm 2.11 \mathrm{Sn} / 31.34 \pm 2.13 \mathrm{Ni}$ and $65.65 \pm 1.34 \mathrm{Sn} / 30.51 \pm 1.42 \mathrm{Ni}$ ratios of weight percentage were determined for the NiSn alloys and for the composites, respectively.

The EDX elemental map of the NiSn-rGO-P3.3 composite coating is presented in Figure 6. As can be observed, the graphene sheets are well distributed over the surface of the coating.

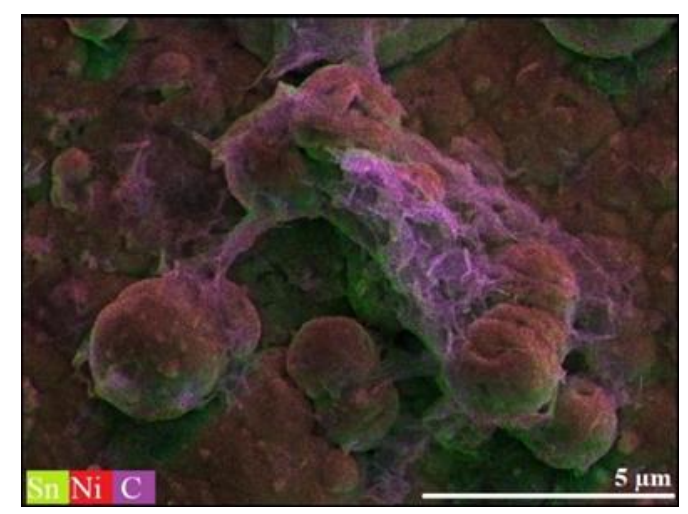

Figure 6. Energy dispersive X-ray (EDX) map of main elements on the composite NiSn-rGO-P3.3.

Additionally, an X-ray line mapping analysis was performed on a sheet presented on the surface of the composite coating (see Figure 7). As can be observed, the recorded line profile exhibits an increase in the carbon content when the analysis is performed on the sheet, while the composition of $\mathrm{Ni}$ and Sn elements remains almost constant. 

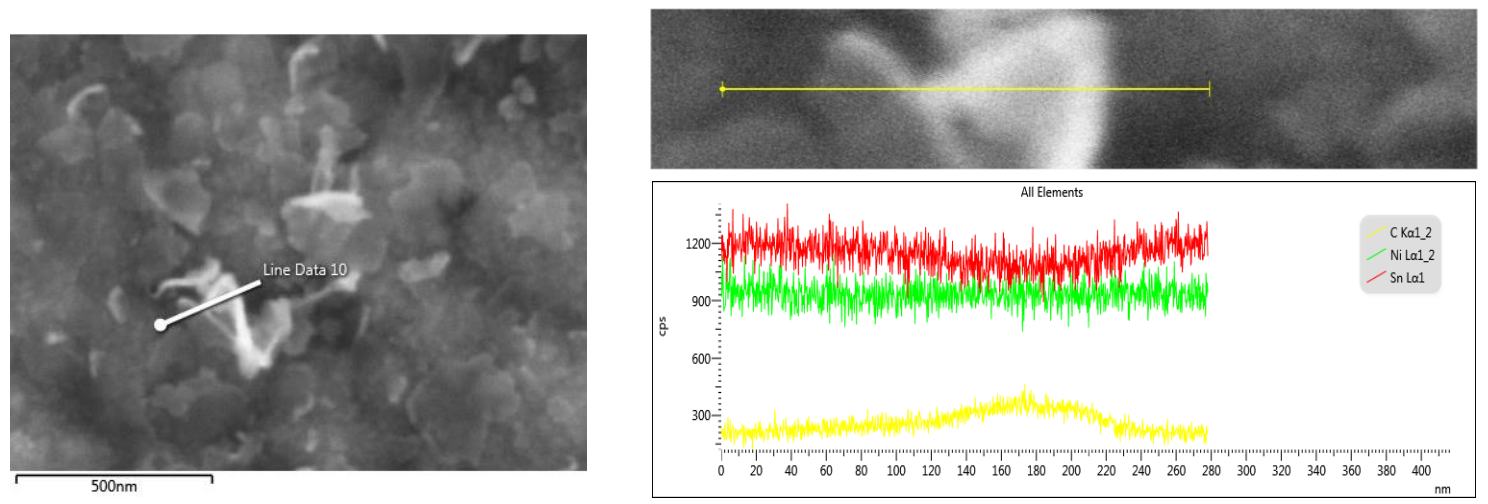

Figure 7. Energy dispersive X-ray (EDX) line scan on the composite NiSn-rGO-P3.3.

From the performed SEM analysis, we were able to observe the presence of the rGO sheets on the surface of the composite coatings. In order to confirm the incorporation of the sheets into the metallic matrix, cross-sectional SEM analysis of the composite coatings was done. As can be seen in Figure 8, the sheets can be clearly observed in the cross-section of the composite coating, confirming the co-deposition of rGO into the metallic NiSn matrix.

\section{Cross-SE}

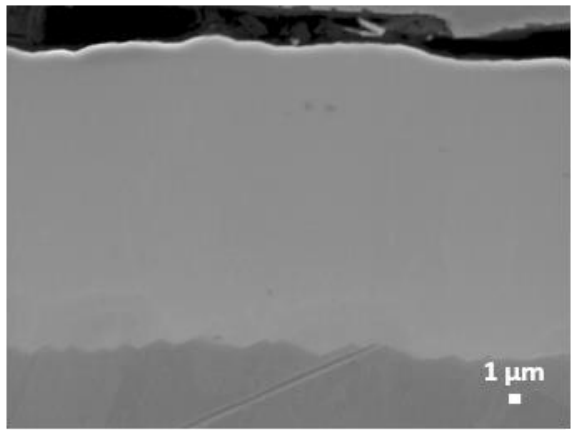

(b)

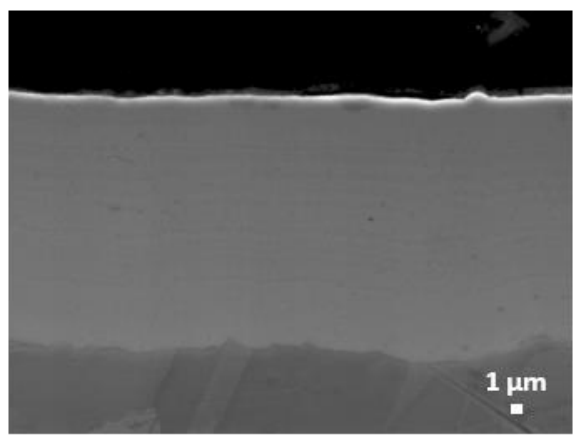

Cross-BSE
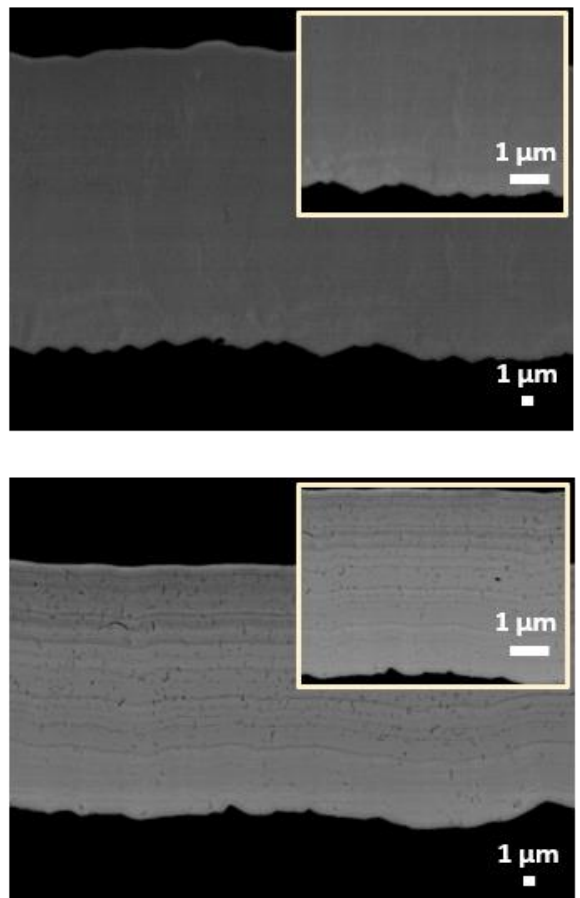

Figure 8. SEM micrographs collected with different detectors, secondary electrons (SE) and backscattered electrons (BSE) in the cross-section of: (a) NiSn-P3.3 and (b) NiSn-rGO-P3.3.

\subsection{Characterization of NiSn-rGO Composite by Raman Spectroscopy}

Raman spectroscopy represents a widely used technique for the characterization of carbon-based materials, being able to provide abundant information regarding chemical modification, crystallite size and crystal disorder [42]. Figure 9 comparatively illustrates the recorded spectra of the commercial graphene oxide and the NiSn-rGO-P3.3 composite coating. 


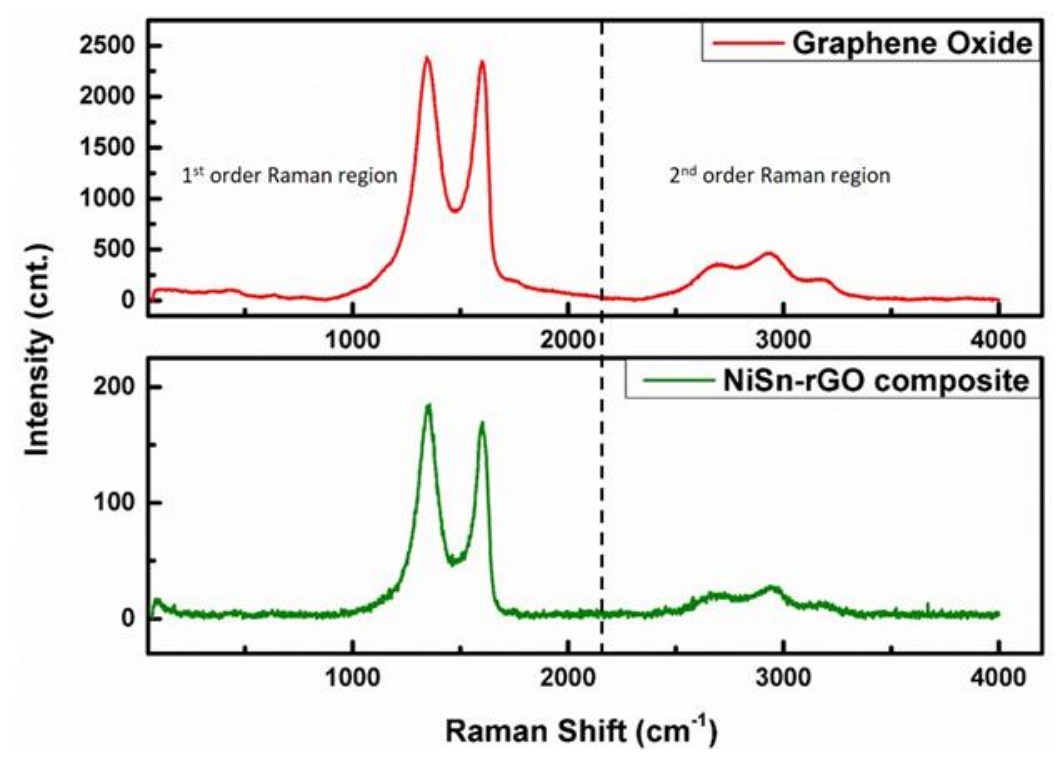

Figure 9. Raman spectra of: (top) graphene oxide and (bottom) the composite NiSn-rGO-P3.3.

The Raman spectra, as expected, reveal the signature of carbon based materials, which consist of three bands, D $\left(\sim 1350 \mathrm{~cm}^{-1}\right), \mathrm{G}\left(\sim 1600 \mathrm{~cm}^{-1}\right)$ and the splitting of 2D Raman active bands centered at $\sim 2900 \mathrm{~cm}^{-1}$. The 1st order region from the Raman spectra of the graphene oxide and the composite material was deconvoluted into five peaks $\left(D_{4}, D_{1}, D_{3}, G\right.$ and $\left.D_{2}\right)$ using a Gauss function (see Figure 10) [43]. Additionally, the Raman spectra of the 2nd order region were deconvoluted in four peaks $\left(G^{*}, 2 D_{1}, D_{1}+G\right.$ and $\left.D_{2}+G\right)$ using Voigt and Gauss functions for graphene oxide and the NiSn-rGO composite respectively, as shown in Figure 11 [44].
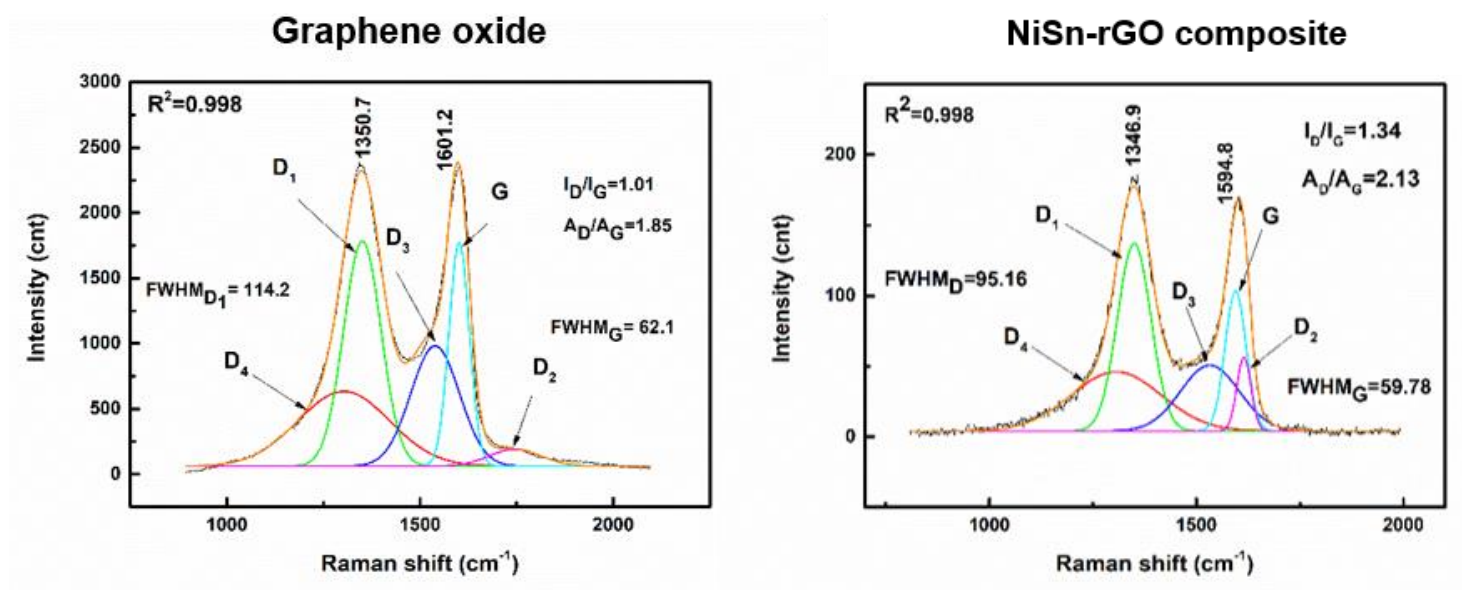

Figure 10. Deconvolution of the peaks from the 1st order Raman region of the signal emitted by graphene oxide and the NiSn-rGO-P3.3 composite. The sum of the deconvolution is marked with an orange line. 

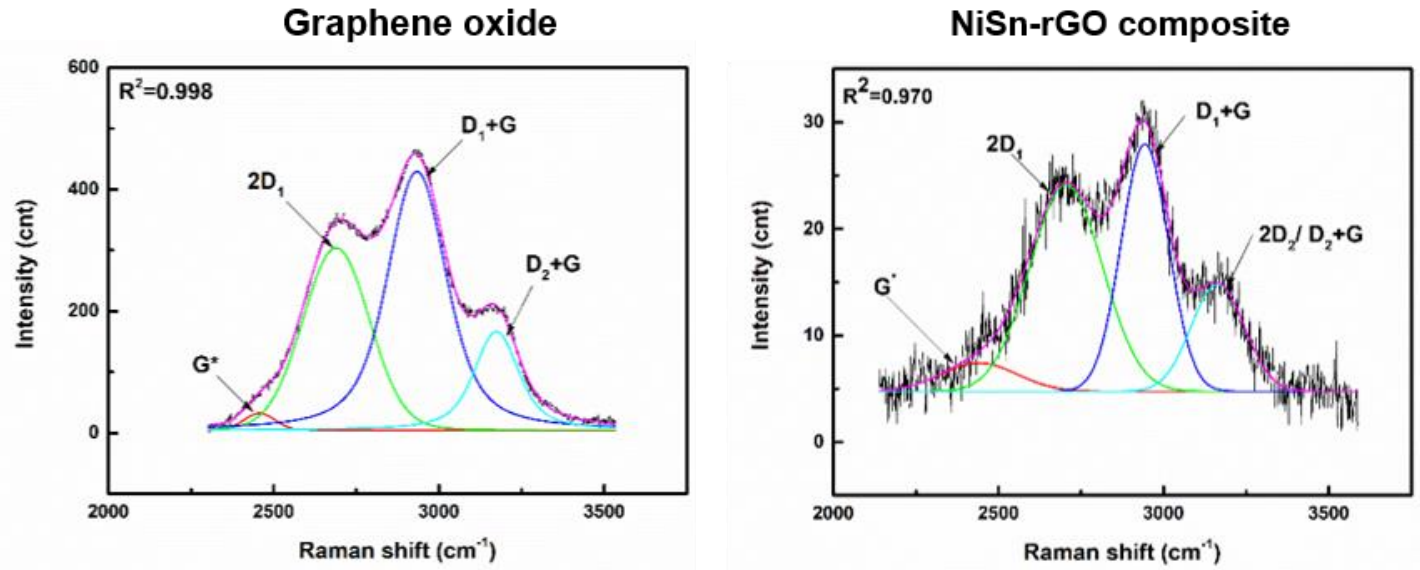

Figure 11. Deconvolution of the peaks from the 2nd order Raman region of graphene oxide and the NiSn-rGO-P3.3 composite. The sum of the deconvolution is shown with an orange line.

The $\mathrm{D}$ band corresponds to the $\mathrm{A}_{1 \mathrm{~g}}$ breathing mode of the disordered $\mathrm{sp}^{2}$-hybridized graphitic structure, while the $G$ band is related to the $E_{2 g}$ breathing mode. The $G$ band originated from the stretching of the $\mathrm{C}-\mathrm{C}$ bond in the hexagonal plane and is common to all $\mathrm{sp}^{2}$ carbon systems. The $2 \mathrm{D}$ band is associated with a phonon process and its position strongly depends on the excitation energy of the laser $[45,46]$.

The degree of disorder and the average size of the in-plane $\mathrm{sp}^{2}$ domains are determined from the intensity ratio of the $\mathrm{D}$ and $\mathrm{G}$ bands $\left(\mathrm{I}_{\mathrm{D}} / \mathrm{I}_{\mathrm{G}}\right)$. The $\mathrm{I}_{\mathrm{D}} / \mathrm{I}_{\mathrm{G}}$ ratio of NiSn-rGO was estimated as 1.34 , which is higher than that of GO (1.01), thus clearly indicating that a change in the structure of the carbon-based material took place during the electrodeposition. The increase in the $\mathrm{I}_{\mathrm{D}} / \mathrm{I}_{\mathrm{G}}$ ratio suggests the formation of new domains of conjugated carbon atoms as a result of the removal of the oxygen-containing groups, indicating that more defects could have been introduced during the electrochemical reduction process. Moreover, a red shift of the $\mathrm{G}$ band is observed in the composite material $\left(1594 \mathrm{~cm}^{-1}\right)$ as compared to $\mathrm{GO}\left(1601 \mathrm{~cm}^{-1}\right)$, which could be attributed to the partial recovery of the hexagonal $\mathrm{sp}^{2}$ carbon network, evidencing the partial electrochemical reduction of GO $[47,48]$.

Additionally, the crystallite size of the $\mathrm{sp}^{2}$ lattice $\left(\mathrm{L}_{\mathrm{a}}\right)$ was determined according to the equation proposed by Pimenta et al. [49]:

$$
\mathrm{L}_{\mathrm{a}}=2.4 \cdot 10^{-10} \cdot \lambda_{\mathrm{L}}^{4} \cdot\left(\frac{\mathrm{I}_{\mathrm{D}}}{\mathrm{I}_{\mathrm{G}}}\right)^{-1}
$$

where $\lambda_{\mathrm{L}}$ is the excitation wavelength. For the commercial graphene oxide, a size value of $19 \mathrm{~nm}$ was determined, while for the composite, the value is $14 \mathrm{~nm}$.

\subsection{XRD Analysis}

The XRD patterns of NiSn-P3.3 alloy and NiSn-rGO-P3.3 composite coating are presented in Figure 12. As can be seen, the revealed patterns are similar. The XRD pattern of the NiSn-rGO was plotted on a logarithmic scale in order to show the low-intensity peaks. The NiSn metastable phase is formed by electrodeposition in both cases [50]. The XRD patterns exhibit a strong peak at around $43^{\circ}$, which corresponds to the (110) plane of the NiSn metastable phase. 


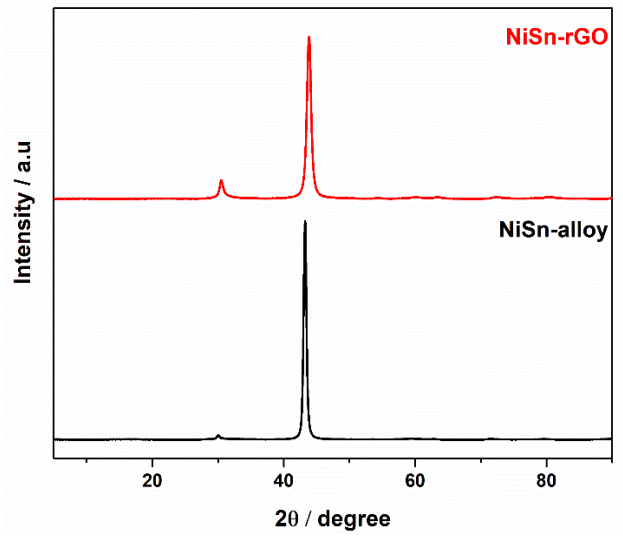

(a)

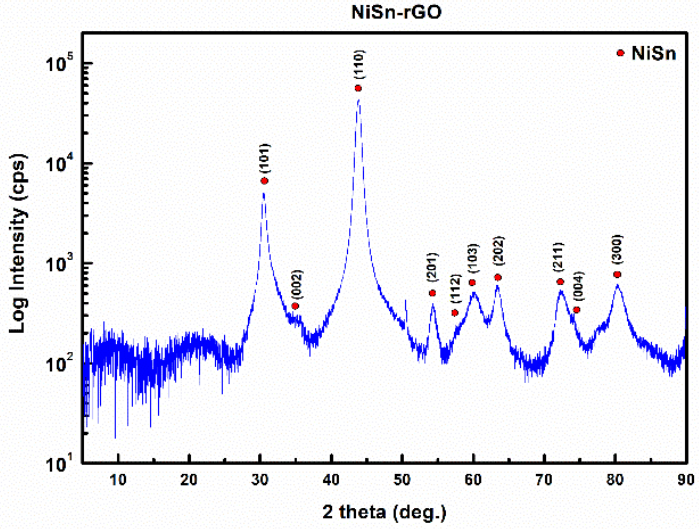

(b)

Figure 12. X-ray diffraction patterns of electrodeposited NiSn-P3.3 alloy and NiSn-rGO-P3.3 composite on copper substrate: (a) linear scale and (b) logarithmic scale.

Scherrer's equation was used to determine the crystallite size. A decrease in the crystallite size was observed when graphene was added to the electrolyte from $18.6 \mathrm{~nm}$ in the NiSn alloy to $12.1 \mathrm{~nm}$ in the composite. This behaviour is consistent with the Raman results. The presence of graphene may increase the nucleation sites and retard the growth of the crystals by affecting the diffusion of the ions to the existing nucleation sites [51].

\subsection{AFM Studies}

The nickel-tin alloy (NiSn-P3.3) and the composite coating (NiSn-rGO-P3.3) were examined by atomic force microscopy (AFM) in contact mode. Figure 13 shows the topography signal acquired in contact mode on an area of $10 \times 10 \mu \mathrm{m}^{2}$ for NiSn alloy and NiSn-rGO composite.

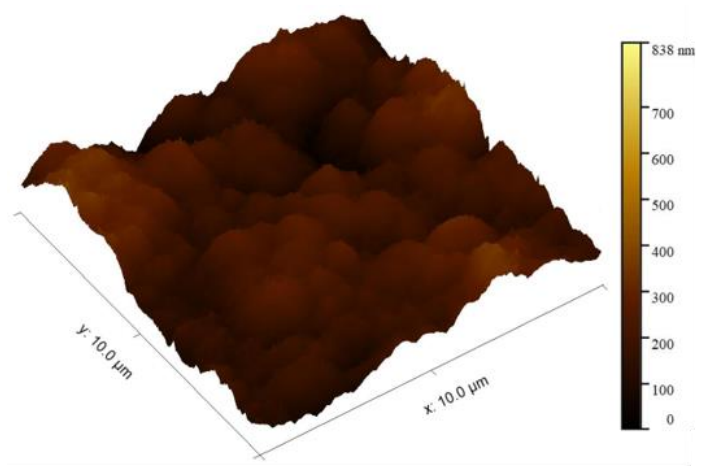

(a)

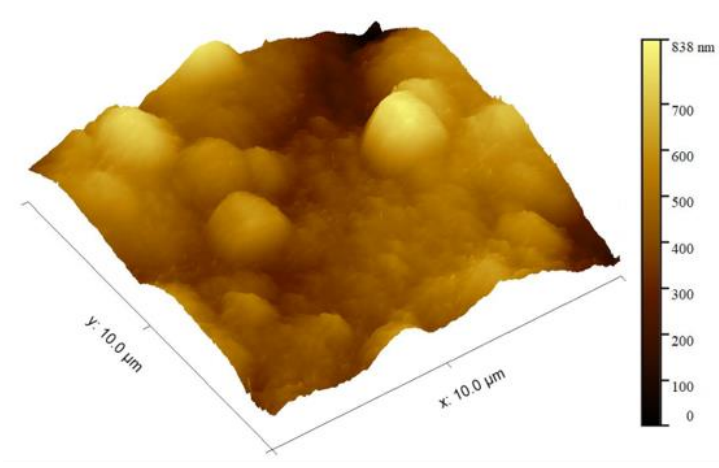

(b)

Figure 13. The $10 \times 10 \mu \mathrm{m}^{2}$ 3D atomic force microscopy (AFM) topography images of (a) NiSn-P3.3-alloy and (b) NiSn-rGO-P3.3.

The values of root mean square roughness $\left(R_{R M S}\right)$ and the roughness average $(R a)$ parameters are presented in Table 4. By comparison, the surface roughness increases with the addition of graphene oxide, also in agreement with the findings reported in [31]. 
Table 4. Statistical roughness quantities calculated for the $2 \mathrm{D}$ topography image $\left(10 \times 10 \mu \mathrm{m}^{2}\right)$ for NiSn-P3.3 alloy and NiSn-rGO-P3.3 composite coatings.

\begin{tabular}{ccc}
\hline Roughness & NiSn-P3.3 Alloy & NiSn-rGO-P3.3 \\
\hline $\mathrm{R}_{\mathrm{RMS}}$ & $60.75 \mathrm{~nm}$ & $117.03 \mathrm{~nm}$ \\
$\mathrm{R}_{\mathrm{a}}$ & $48.63 \mathrm{~nm}$ & $91.12 \mathrm{~nm}$ \\
\hline
\end{tabular}

$\mathrm{R}_{\mathrm{RMS}}$ : root mean square roughness and Ra: roughness average.

Additionally, the topography, lateral force and current signals were acquired simultaneously in contact mode on an area of $3 \times 3 \mu \mathrm{m}^{2}$, as illustrated in Figure 14 .

(a)

Surface morphology

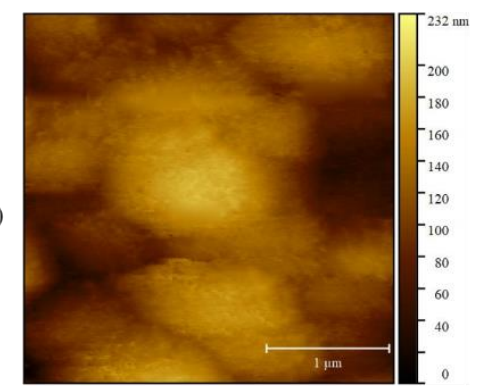

(b)

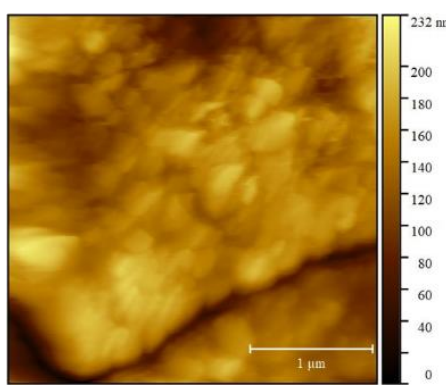

Friction force variation
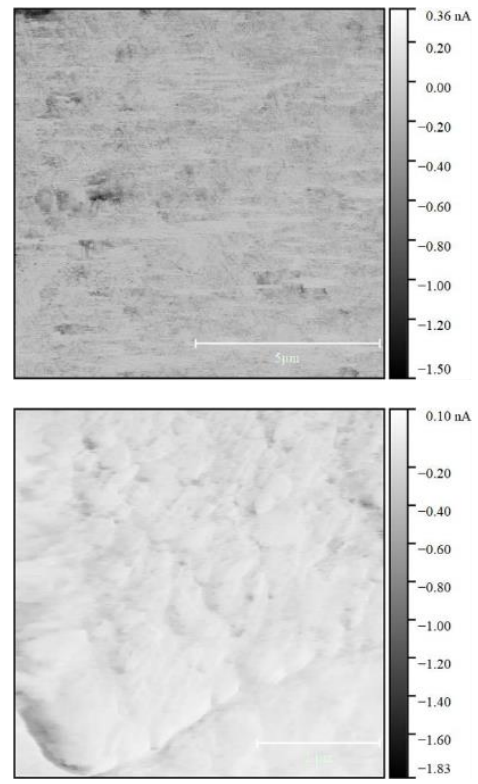

Electrical conductivity with $+4 \mathrm{~V}$ applied bias voltage
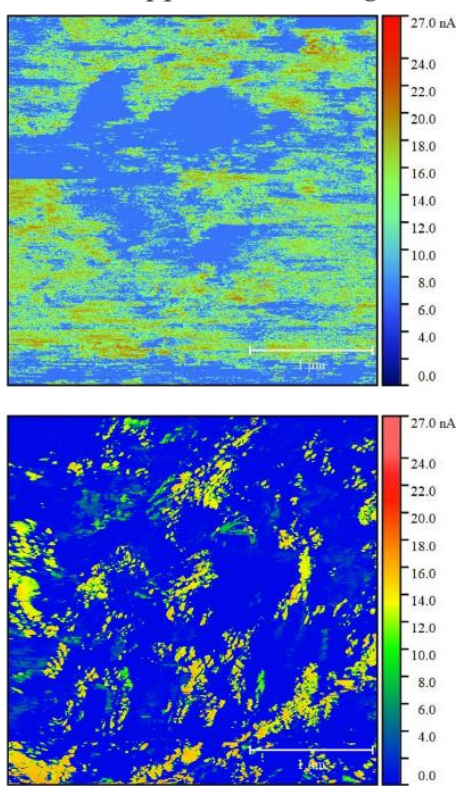

Figure 14. The $3 \times 3 \mu \mathrm{m}^{2} 2 \mathrm{D}$ AFM images of: (a) NiSn-P3.3-alloy and (b) NiSn-rGO-P3.3 composite.

The topography images show a surface with round particles for both materials. However, the localization of the rGO sheets was not possible in the topographic image nor in the friction force map, since there are no contrasting regions in the expected shape.

With the conducting atomic force microscopy (C-AFM), using an electrically conductive probe tip in contact mode, it was possible to map the changes in the surface conductivity, as is presented in Figure 14. The high conductivity zones are red, while the lower conductivity regions are blue. As can be seen in Figure 14, the NiSn-P3.3-alloy exhibited larger regions of higher electrical conductivity (12 nA-16 nA) than the NiSn-rGO-P3.3 composite, whose' largest area is described by lower electrical current values (below $11 \mathrm{nA}$ ). The decrease in the electrical conductivity of the composite could be attributed to an imperfect removal of the oxygen groups from the GO sheets. Table 5 presents the values of the $I_{a}$ and $I_{R M S}$ related to the conductivity studies. An increase in the $I_{a}$ and $I_{\text {RMS }}$ electrical parameters was noticed in the composite material $\left(\mathrm{I}_{\mathrm{a}}=3.09 \mathrm{nA}\right.$ and $\left.\mathrm{I}_{\mathrm{RMS}}=4.29 \mathrm{nA}\right)$ as compared to the pure NiSn alloy, where values of $2.87 \mathrm{nA}$ for $\mathrm{I}_{\mathrm{a}}$ and $3.17 \mathrm{nA}$ for $\mathrm{I}_{\text {RMS }}$ were found. The increase in the $\mathrm{I}_{\mathrm{a}}$ and $\mathrm{I}_{\mathrm{RMS}}$ electrical parameters show an increase in the measured electrical current value deviation from the mean current value on the conductivity map. This increase could be the result of the presence of non-reduced GO sheets, that are behaving as insulators. 
Table 5. Electrical conductivity values for the specimens from Figure 14.

\begin{tabular}{|c|c|c|c|}
\hline \multirow[t]{2}{*}{ Sample } & \multirow[t]{2}{*}{ Scan Area $\left(\mu \mathrm{m}^{2}\right)$} & \multicolumn{2}{|c|}{$\begin{array}{c}\text { Electrical Conductivity } \\
\text { Expressed as Electric Current }\end{array}$} \\
\hline & & $\mathbf{I}_{\text {RMS }}(\mathbf{n A})$ & Ia $(\mathrm{nA})$ \\
\hline NiSn-P3.3 alloy & $3 \times 3$ & 3.17 & 2.87 \\
\hline NiSn-rGO-P3.3 composite & $3 \times 3$ & 4.29 & 3.09 \\
\hline
\end{tabular}

$\mathrm{I}_{\mathrm{RMS}}$ : root mean square electrical current and $\mathrm{I}_{\mathrm{a}}$ : average electrical current.

\subsection{Corrosion Behavior of the NiSn Alloy and NiSn-rGO Composite Coatings}

The corrosion performance of the electrodeposited NiSn-P3.3 alloy and NiSn-rGO-P3.3 composite coatings was assessed by recording of the potentiodynamic polarization curves and the electrochemical impedance spectroscopy (EIS) spectra in aerated $0.5 \mathrm{M} \mathrm{NaCl}$ solution after different periods of immersion at room temperature. Prior to each experiment, the electrode potential of the specimen was allowed to stabilize in the electrolyte until a constant value of open circuit potential was obtained.

The semilogarithmic Tafel curves of potentiodynamic polarization measurements performed in $0.5 \mathrm{M} \mathrm{NaCl}$ after different periods of exposure are illustrated in Figure 15. The corrosion potential ( $\left.\mathrm{E}_{\text {corr }}\right)$ and the corrosion current density $\left(\mathrm{i}_{\text {corr }}\right.$ ) were determined by extrapolation from the Tafel plots and the obtained values are listed in Table 6. On the initial moment of immersion, the NiSn-rGO composite coating showed better corrosion resistance as compared to NiSn alloy one because $\mathrm{E}_{\text {corr }}$ shifted to more positive values and corrosion current density decreased by more than an order of magnitude. After longer immersion periods, of 168 and $336 \mathrm{~h}$ of exposure respectively, to the aggressive medium, the values of the corrosion potential and corrosion current density are quite similar, regardless of the coating type. This phenomenon might be due to the activation of some defects present on the NiSn-rGO surface (not initially visible). The non-uniform distribution of the rGO within the alloy matrix is not excluded, thus allowing the diffusion of the aggressive $\mathrm{Cl}^{-}$ions through the layer.
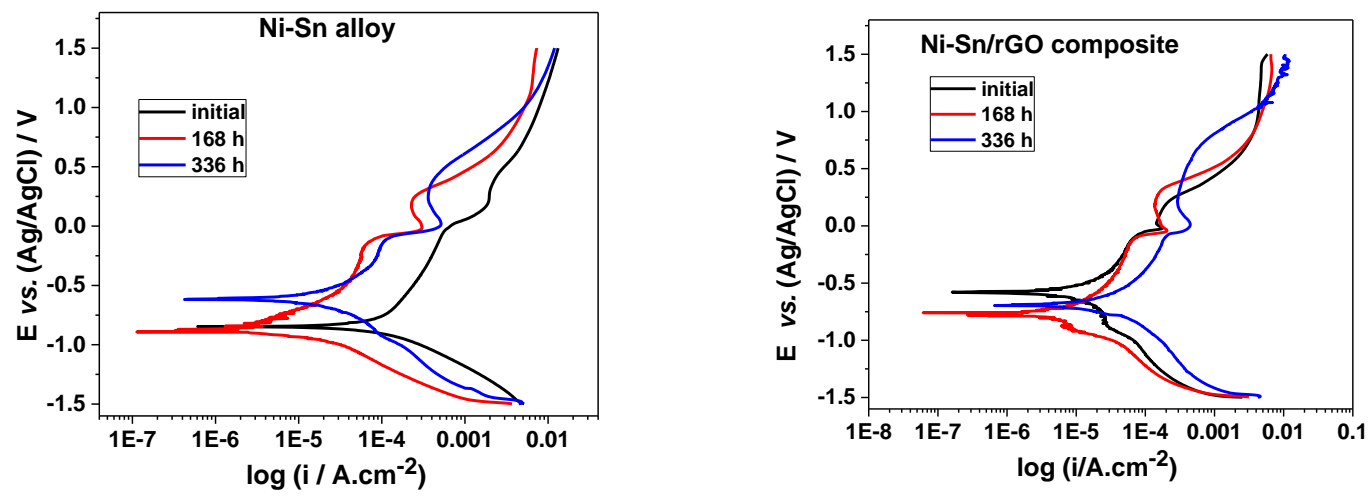

Figure 15. Polarization curves in semilogarithmic coordinates in $0.5 \mathrm{M} \mathrm{NaCl}$ for different periods of immersion $\left(25^{\circ} \mathrm{C}, 5 \mathrm{mV} \mathrm{s}^{-1}\right)$.

Table 6. Values of corrosion parameters resulting from polarization curves in $0.5 \mathrm{M} \mathrm{NaCl}$ for NiSn-P3.3 alloy and NiSn-rGO-P3.3 composite coatings after different conditioning periods.

\begin{tabular}{|c|c|c|c|c|}
\hline \multirow[b]{2}{*}{$\begin{array}{l}\text { Immersion } \\
\text { Period }\end{array}$} & \multicolumn{2}{|c|}{ NiSn-P3.3 Alloy } & \multicolumn{2}{|c|}{ NiSn-rGO-P3.3 Composite } \\
\hline & $\begin{array}{c}\text { E }_{\text {corr }} \\
\text { V/Ag/AgCl }\end{array}$ & $\begin{array}{c}\mathbf{i}_{\text {corr }} \\
\mu \mathrm{A} / \mathrm{cm}^{2}\end{array}$ & $\begin{array}{c}\text { E }_{\text {corr' }} \\
\text { V/Ag/AgCl }\end{array}$ & $\begin{array}{c}\mathrm{i}_{\text {corr, }} \\
\mu \mathrm{A} / \mathrm{cm}^{2}\end{array}$ \\
\hline Initial & $-0.84 \pm 0.002$ & $170 \pm 2.16$ & $-0.57 \pm 0.001$ & $10.6 \pm 0.16$ \\
\hline $168 \mathrm{~h}$ & $-0.86 \pm 0.001$ & $11.2 \pm 0.31$ & $-0.76 \pm 0.003$ & $9.5 \pm 0.22$ \\
\hline $336 \mathrm{~h}$ & $-0.61 \pm 0.01$ & $31.6 \pm 0.28$ & $-0.67 \pm 0.001$ & $34 \pm 0.87$ \\
\hline
\end{tabular}


The electrochemical impedance spectra of NiSn-P3.3 alloy and NiSn-rGO-P3.3 composite coatings recorded at open circuit potential (OCP) in $0.5 \mathrm{M} \mathrm{NaCl}$ solution for different immersion periods are illustrated in Figure 16 as Nyquist and Bode plots. All Nyquist diagrams show a semicircle arc in the relatively high-frequency range. The diameter of the semicircles is associated with the charge-transfer resistance $\left(\mathrm{R}_{\mathrm{ct}}\right)$, together with film resistance $\left(\mathrm{R}_{\mathrm{F}}\right)$, which may be correlated to the rate of corrosion: the larger the resistance, the lower is the corrosion rate. A larger diameter for NiSn-rGO in the initial state was noticed, which was almost maintained after $168 \mathrm{~h}$ of corrosion but became five times smaller after $336 \mathrm{~h}$ of corrosive attack. Bode plots show in all cases values of phase angle maxima in the range $\left(-50^{\circ}--60^{\circ}\right)$ as well as similar dependences of impedance modulus vs. frequency.
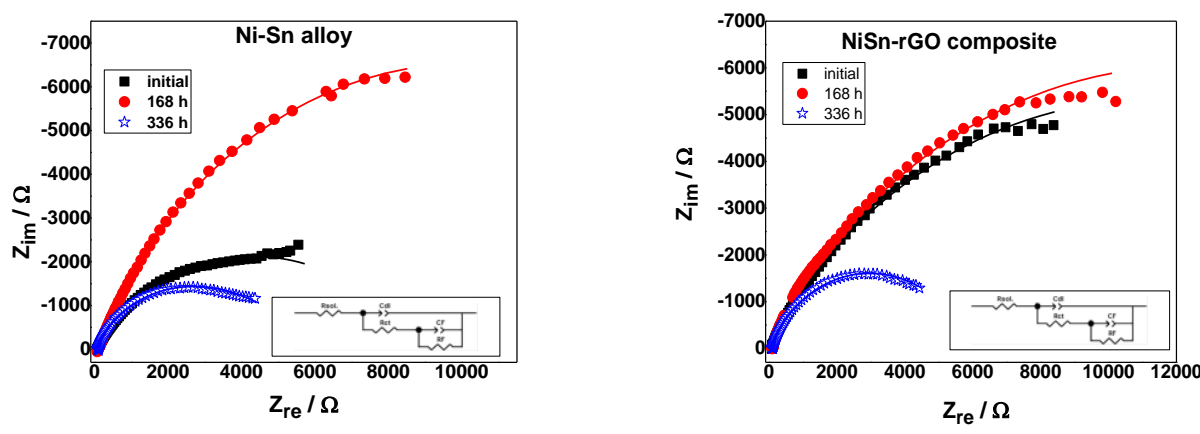

(a)
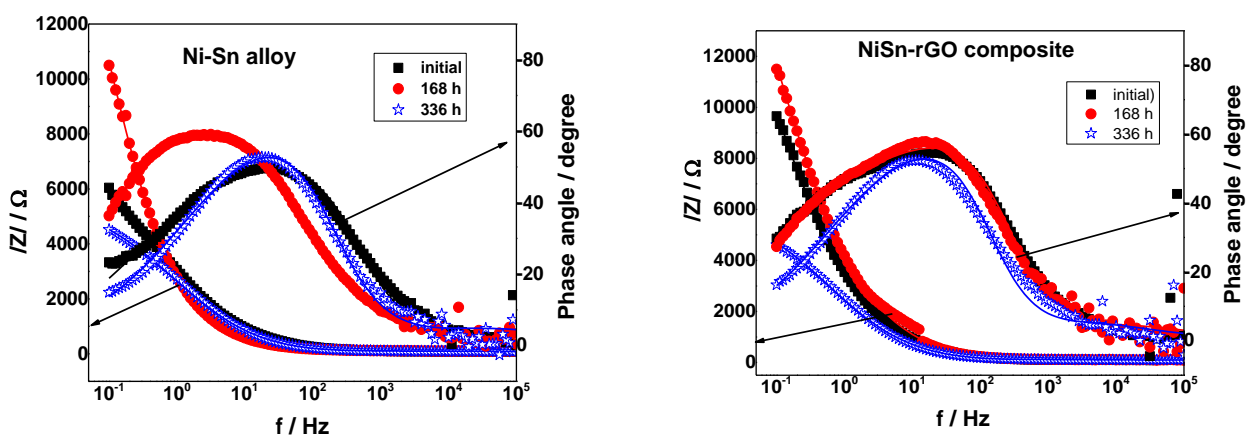

(b)

Figure 16. (a) Nyquist plots and (b) Bode plots for Ni-Sn alloy and NiSn-rGO composite coatings in $0.5 \mathrm{M} \mathrm{NaCl}$ at open circuit potential, after different periods of immersion (solid lines are the fit of the experimental data using the inserted equivalent circuit).

The equivalent electrical circuit (EC) to describe corrosion behaviour of NiSn-P3.3 alloy and NiSn-rGO-P3.3 composite coatings in the $\mathrm{NaCl}$ solution is shown in each inset of Figure 16a.

The process can be modeled as a double-layer capacitor $\left(\mathrm{C}_{\mathrm{dl}}\right)$ in parallel with a charge transfer resistor $\left(\mathrm{R}_{\mathrm{CT}}\right)$, which is in series with a circuit containing a film capacitor $\left(\mathrm{C}_{\mathrm{F}}\right)$ in parallel with a film resistor $\left(R_{F}\right)$, all in series with the solution ohmic resistance $\left(R_{s o l}\right)$. We used, in the model, the constant phase element (CPE) instead of true capacitances [52,53]. The values of important impedance parameters, which are obtained by fitting the impedance data with Zview software using the proposed EC, are listed in Table 7. 
Table 7. Fitting results of electrochemical impedance spectroscopy (EIS) spectra for NiSn-P3.3 alloy and NiSn-rGO-P3.3 composite coatings after exposure to $0.5 \mathrm{M} \mathrm{NaCl}$ solution for various times using the proposed equivalent circuit.

\begin{tabular}{ccccc}
\hline \multirow{2}{*}{ Immersion Period } & \multicolumn{2}{c}{ NiSn-P3.3 Alloy } & \multicolumn{2}{c}{ NiSn-rGO-P3.3 Composite } \\
& $\mathbf{R}_{\mathbf{c t}}, \boldsymbol{\Omega}$ & $\mathbf{R}_{\mathbf{F}}, \boldsymbol{\Omega}$ & $\mathbf{R}_{\mathbf{c t}}, \boldsymbol{\Omega}$ & $\mathbf{R}_{\mathbf{F}}, \boldsymbol{\Omega}$ \\
\hline Initial & 29 & 8715 & 13 & 23,707 \\
$168 \mathrm{~h}$ & 33 & 20,160 & 35 & 25,142 \\
$336 \mathrm{~h}$ & 38 & 5890 & 40 & 6055 \\
\hline
\end{tabular}

According to the fitting results, coating resistances for the initial moment of immersion of about $8.7 \mathrm{k} \Omega$ for NiSn-P3.3 alloy and of around $23.7 \mathrm{k} \Omega$ for the NiSn-rGO-P3.3 composite was estimated, in good agreement with the obtained results based on the potentiodynamic polarization curves. As the immersion period increased to $168 \mathrm{~h}$, higher values of $R_{F}$ were noticed for both investigated coatings, suggesting the formation of a protective passive film on the surface. However, after longer immersion periods of $336 \mathrm{~h}$, a decrease in the film resistance was observed for both the NiSn alloy and NiSn-rGO. Moreover, the composite material showed a slightly higher value of the film resistance as compared to the bare alloy.

After $336 \mathrm{~h}$ of immersion in $0.5 \mathrm{M} \mathrm{NaCl}$, the morphology of the sample was analyzed by SEM, as illustrated in Figure 17. The presence of a thin film is observed on top of both samples, evidencing a nano-petal like morphology, which may be ascribed to the formation of a nickel oxy-hydroxide layer. A similar morphology was reported in [54] for $\mathrm{Ni}(\mathrm{OH})_{2}$ nanostructures formed as corrosion products on Ni nanofoams.

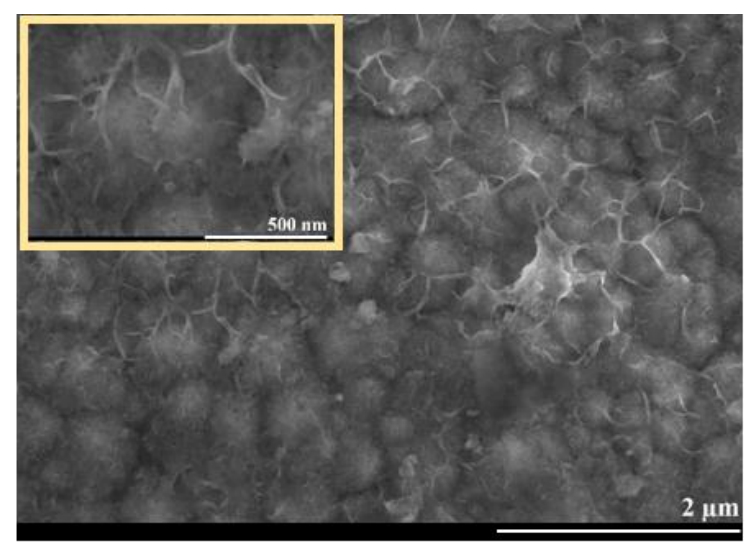

(a)

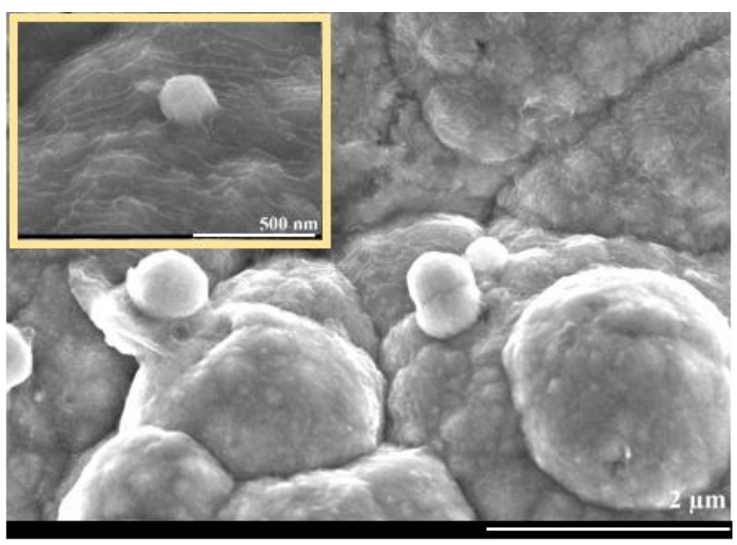

(b)

Figure 17. SEM SE micrographs of (a) NiSn-P3.3 alloy and (b) NiSn-rGO-P3.3 composite after $336 \mathrm{~h}$ of immersion in $0.5 \mathrm{M} \mathrm{NaCl}$.

\section{Conclusions}

The above presented investigations show, for the first time, that the electrodeposition of NiSn-rGO composite coatings on copper substrates can be successfully performed with choline chloride: ethylene glycol (1:2 molar) deep eutectic solvent.

Uniform NiSn-rGO composite coatings, possessing an adequate adhesion to the $\mathrm{Cu}$ metallic substrate, were electrodeposited under pulse current conditions. The successful incorporation of the carbon-based material into the metallic matrix was evidenced by Raman spectroscopy and cross-section SEM analyses. The addition of the graphene oxide sheets in the NiSn alloy matrix led to changes in the surface morphology, grain size and surface roughness parameters. Additionally, an increase in the variation of the electrical current values revealed by $I_{a}$ and $I_{R M S}$ electrical parameters and a 
slight improvement of the corrosion performance was noticed in the case of the NiSn-rGO composite coatings when compared to pure NiSn alloy ones.

Some other investigations related to the use of more concentrated GO-based DESs and their influence on the final properties of the composite coatings, as well as the development of other rGO-based composites involving other metallic matrices such as silver and indium alloys, particularly with applications in electronics, are scheduled for further investigations.

Author Contributions: Experimental investigation, writing_original draft preparation, S.P.R.; XRD and AFM analysis, A.G.P.; electrodeposition methodology, A.P.; project administration, A.C.; electrodeposition methodology, analysis, S.C.; cross section analysis and discussion C.Z.; SEM, AFM, XRD, resources, discussion, M.E.; writing-review, discussion, supervision, T.V.; conceptualization and analysis, writing-review and editing, L.A. All authors have read and agreed to the published version of the manuscript.

Funding: This research was funded by the European Union's Horizon 2020 research and innovation programme under the MARIE- SKŁODOWSKA-CURIE, grant number 764977 and by the Romanian Ministry of Education and Research, under the following ECSEL-H2020 Projects: OCEAN12 (Ctr. no. 9/1.1.3H/20.01.2020, POC-SMIS code 129948) and MADEin4 (Ctr. no. 8/1.1.3H/06.01.2020, POC-SMIS code 128826).

Acknowledgments: The PhD student expresses her appreciation to the Department of Materials and Manufacturing of Jönköping University for the kind permission to use the laboratories systems.

Conflicts of Interest: The authors declare no conflict of interest.

\section{References}

1. Ray, S.C. Applications of Graphene and Graphene-Oxide Based Nanomaterials, 1st ed.; Elsevier Inc.: Amsterdam, The Netherlands; William Andrew Publishing: Waltham, MA, USA, 2015; pp. 1-38.

2. Johnson, D.; Dobson, B.; Coleman, K. A manufacturing perspective on graphene dispersions. Curr. Opin. Colloid Interface Sci. 2015, 20, 367-382. [CrossRef]

3. Hussain, A.K.; Al Naib, U.M.B. Recent developments in graphene based metal matrix composite coatings for corrosion protection application: A review. J. Met. Mater. Miner. 2019, 29, 1-9.

4. Li, R.; Liang, J.; Hou, Y.; Chu, Q. Enhanced corrosion performance of Zn coating by incorporating graphene oxide electrodeposited from deep eutectic solvent. RSC Adv. 2015, 5, 60698-60707. [CrossRef]

5. Ambrosi, A.; Pumera, M. The structural stability of graphene anticorrosion coating materials is compromised at low potentials. Chem. Eur. J. 2015, 21, 7896-7901. [CrossRef] [PubMed]

6. Dideikin, A.T.; Vul, A.Y. Graphene oxide and derivatives: The place in graphene family. Front. Phys. 2019, 6, 149. [CrossRef]

7. Smith, A.; La Chance, A.; Zeng, S.; Liu, B.; Sun, L. Synthesis, properties, and applications of graphene oxide/reduced graphene oxide and their nanocomposites. Nano Mater. Sci. 2019, 1, 31-47. [CrossRef]

8. Stankovich, S.; Dikin, D.; Piner, R.; Kohlhaas, K.; Kleinhammes, A.; Jia, Y.; Wu, Y.; Nguyen, S.; Ruoff, R. Synthesis of graphene-based nanosheets via chemical reduction of exfoliated graphite oxide. Carbon 2007, 45, 1558-1565. [CrossRef]

9. Ping, J.; Wang, Y.; Fan, K.; Wu, J.; Ying, Y. Direct Electrochemical Reduction Of Graphene oxide on ionic liquid doped screen-printed electrode and its electrochemical biosensing application. Biosens. Bioelectron. 2011, 28, 204-209. [CrossRef]

10. Toh, S.; Loh, K.; Kamarudin, S.; Daud, W. Graphene production via electrochemical reduction of graphene oxide: Synthesis and characterisation. Chem. Eng. J. 2014, 251, 422-434. [CrossRef]

11. Chen, L.; Tang, Y.; Wang, K.; Liu, C.; Luo, S. Direct electrodeposition of reduced graphene oxide on glassy carbon electrode and its electrochemical application. Electrochem. Commun. 2011, 13, 133-137. [CrossRef]

12. Jana, A.; Scheer, E.; Polarz, S. Synthesis of graphene-transition metal oxide hybrid nanoparticles and their application in various fields. Beilstein J. Nanotechnol. 2017, 8, 688-714. [CrossRef] [PubMed]

13. Kuang, D.; Xu, L.; Liu, L.; Hu, W.; Wu, Y. Graphene-nickel composites. App. Surf. Sci. 2013, 273, 484-490. [CrossRef]

14. Kumar, C.M.P.; Venkatesha, T.V.; Shabadi, R. Preparation and corrosion behavior of Ni and Ni-graphene composite coatings. Mater. Res. Bull. 2013, 48, 1477-1483. [CrossRef] 
15. Yu, Q.Y.; Zhang, Y.X.; Liu, Z.Z.; Zeng, Z.X.; Wu, X.D.; Xue, Q.J. Effect of $\mathrm{N}_{2} \mathrm{H}_{4}$ on electrodeposition of Ni-graphene composite coatings and their corrosion resistance property. Mater. Sci. Forum 2015, 816, 192-199. [CrossRef]

16. Szeptycka, B.; Gajewska-Midzialek, A.; Babul, T. Electrodeposition and corrosion resistance of Ni-graphene composite coatings. J. Mater. Eng. Perform. 2016, 25, 3134-3138. [CrossRef]

17. Jabbar, A.; Yasin, G.; Khan, W.Q.; Anwar, M.Y.; Korai, R.M.; Nizamb, M.N.; Muhyodinb, G. Electrochemical deposition of nickel graphene composite coatings: Effect of deposition temperature on its surface morphology and corrosion resistance. RSC Adv. 2017, 7, 31100-31109. [CrossRef]

18. Ding, S.; Xiang, T.; Li, C.; Zheng, S.; Wang, J.; Zhang, M.; Dong, C.; Chan, W. Fabrication of self-cleaning super-hydrophobic nickel/graphene hybrid film with improved corrosion resistance on mild steel. Mater. Des. 2017, 117, 280-288. [CrossRef]

19. Singh, S.K.; Samanta, S.; Das, A.K.; Sahoo, R.R. Tribological investigation of Ni-graphene oxide composite coating produced by pulsed electrodeposition. Surf. Interfaces 2018, 12, 61-70. [CrossRef]

20. Karimi, M.A.; Tavallali, H. Corrosion resistance of nickel-zinc/graphene composite coating on mild steel. IJASEAT 2018, 6, 5-8.

21. Yasin, G.; Khan, M.A.; Arif, M.; Shakeel, M.; Mehtab, T.; Khan, W.Q.; Koral, R.M.; Zuo, Y.; Abbas, Z. Synthesis of spheres-like $\mathrm{Ni} /$ graphene nanocomposite as an efficient anti-corrosive coating; effect of graphene content on its morphology and mechanical properties. J. Alloys Compd. 2018, 755, 79-88. [CrossRef]

22. Singh, S.K.; Samanta, S.; Das, A.K.; Sahoo, R.R. Electrodeposited SiC-graphene oxide composite in nickel matrix for improved tribological applications. Surf. Topogr. Metrol. 2019, 7, 035004. [CrossRef]

23. Singh, S.K.; Samanta, S.; Das, A.K.; Sahoo, R.R. Hydrophobic reduced graphene oxide-based Ni coating for improved tribological application. J. Mater. Eng. Perform. 2019, 28, 3704-3713. [CrossRef]

24. Xu, L.; Wang, R.; Gen, M.; Lu, L.; Han, G. Preparation and properties of graphene/nickel composite coating based on textured surface of aluminum alloy. Materials 2019, 12, 3240. [CrossRef] [PubMed]

25. Luo, Y.; Sun, Y.; Gu, Y.; Zhao, J.; Liang, J.; Yue, W. Enhanced tribological performance of a Ni/GO-coated 2024 alloy. J. Mater. Eng. Perform 2020, 29, 2947-2956. [CrossRef]

26. Berlia, R.; Punith Kumar, M.K.; Srivastava, C. Electrochemical behavior of Sn-graphene composite coating. RSC Adv. 2015, 5, 71413-71418. [CrossRef]

27. Endres, F.; Abbott, A.P.; MacFarlane, D.R. Electrodeposition of Metals Using Ionic Liquids; Wiley-VCH: Weinheim, Germany, 2008.

28. Martis, P.; Dilimon, V.S.; Delhalle, J.; Mekhalif, Z. Electro-generated nickel/carbon nanotube composites in ionic liquid. Electrochim. Acta 2010, 55, 5407-5410. [CrossRef]

29. Abbott, A.; McKenzie, K. Application of ionic liquids to the electrodeposition of metals. Phys. Chem. Chem. Phys. 2006, 8, 4265. [CrossRef]

30. Haerens, K.; Matthijs, E.; Chmielarz, A.; Van der Bruggen, B. The use of ionic liquids based on choline chloride for metal deposition: A green alternative? J. Environ. Manag. 2009, 90, 3245-3252. [CrossRef]

31. Brandão, A.T.S.C.; Anicai, L.; Lazar, O.A.; Rosoiu, S.; Pantazi, A.; Costa, R.; Enachescu, M.; Pereira, C.M.; Silva, A.F. Electrodeposition of $\mathrm{Sn}$ and $\mathrm{Sn}$ composites with carbon materials using choline chloride-based ionic liquids. Coatings 2019, 9, 798. [CrossRef]

32. Jalota, S. Tin-nickel alloy plating. Met. Fin. 2002, 100, 307-310. [CrossRef]

33. Cojocaru, A.; Costovici, S.; Anicai, L.; Visan, T. Studies of cathodic processes during NiSn alloy deposition using choline chloride based ionic liquids. Metal. Int. 2009, 14, 1-11.

34. Vijayakumar, J.; Mohan, S.; Kumar, S.; Suseendiran, S.; Pavithra, S. Electrodeposition of Ni-Co-Sn alloy from choline chloride-based deep eutectic solvent and characterization as cathode for hydrogen evolution in alkaline solution. Int. J. Hydrog. Energ. 2013, 38, 10208-10214. [CrossRef]

35. Anicai, L.; Petica, A.; Costovici, S.; Prioteasa, P.; Visan, T. Electrodeposition of Sn and NiSn alloys coatings using choline chloride based ionic liquids-Evaluation of corrosion behavior. Electrochim. Acta 2013, 114, 868-877. [CrossRef]

36. Fashu, S.; Mudzingwa, L.; Khan, R.; Tozvireva, M. Electrodeposition of high corrosion resistant Ni-Sn-P alloy coatings from an ionic liquid based on choline chloride. T. I. Met. Finish. 2018, 96, 20-26. [CrossRef]

37. Rosoiu, S.P.; Pantazi, A.G.; Petica, A.; Cojocaru, A.; Costovici, S.; Zanella, C.; Visan, T.; Anicai, L.; Enachescu, M. Comparative study of Ni-Sn alloys electrodeposited from choline chloride-based ionic liquids in direct and pulsed current. Coatings 2019, 9, 801. [CrossRef] 
38. Rekha, M.Y.; Kamboj, A.; Srivastava, C. Electrochemical behavior of SnNi-graphene oxide composite coatings. Thin Solid Films 2018, 653, 82-92. [CrossRef]

39. Al-Gahouari, T.; Bodkhe, G.; Sayyad, P.; Ingle, N.; Mahadik, M.; Shirsat, S.M.; Deshmukh, M.; Musahwar, N.; Shirsat, M. Electrochemical sensor: L-Cysteine induced selectivity enhancement of electrochemically reduced graphene oxide-multiwalled carbon nanotubes hybrid for detection of lead ( $\mathrm{Pb} 2+)$ ions. Front. Mater. 2020, 7, 1-13. [CrossRef]

40. Badea, M.L.; Cojocaru, A.; Anicai, L. Electrode processes in ionic liquid solvents as mixtures of choline chloride with urea, ethylene glycol or malonic acid. UPB Sci. Bull. Ser. B 2014, 76, 21-32.

41. Vieira, L.; Burt, J.; Richardson, P.; Schloffer, D.; Fuchs, D.; Moser, A.; Bartlett, P.; Reid, G.; Gollas, B. Tin, Bismuth, and tin-bismuth alloy electrodeposition from chlorometalate salts in deep eutectic solvents. Chem. Open 2017, 6, 393-401. [CrossRef]

42. Saito, R.; Hofmann, M.; Dresselhaus, G.; Jorio, A.; Dresselhaus, M. Raman spectroscopy of graphene and carbon nanotubes. Adv. Phys. 2011, 60, 413-550. [CrossRef]

43. Claramunt, S.; Varea, A.; López-Díaz, D.; Velázquez, M.; Cornet, A.; Cirera, A. The importance of interbands on the interpretation of the Raman spectrum of graphene oxide. J. Phys. Chem. C 2015, 119, 10123-10129. [CrossRef]

44. Kaniyoor, A.; Ramaprabhu, S. A Raman spectroscopic investigation of graphite oxide derived graphene. AIP Adv. 2012, 2, 032183. [CrossRef]

45. Ferrari, A. Raman spectroscopy of graphene and graphite: Disorder, electron-phonon coupling, doping and nonadiabatic effects. Solid State Commun. 2007, 143, 47-57. [CrossRef]

46. Mahmood, A. Laser based fabrication of graphene. In Advances in Graphene Science; InTech: Rijeka, Croatia, 2014; p. 84.

47. Eckmann, A.; Felten, A.; Mishchenko, A.; Britnell, L.; Krupke, R.; Novoselov, K.; Casiraghi, C. Probing the nature of defects in graphene by Raman spectroscopy. Nano Lett. 2012, 12, 3925-3930. [CrossRef]

48. Marrani, A.; Zanoni, R.; Schrebler, R.; Dalchiele, E. Toward graphene/silicon interface via controlled electrochemical reduction of graphene oxide. J. Phys. Chem. C 2017, 121, 5675-5683. [CrossRef]

49. Pimenta, M.; Dresselhaus, G.; Dresselhaus, M.; Cançado, L.; Jorio, A.; Saito, R. Studying disorder in graphite-based systems by Raman spectroscopy. Phys. Chem. Chem. Phys. 2007, 9, 1276-1290. [CrossRef] [PubMed]

50. Rooksby, H. An X-Ray study of tin-nickel electrodeposits. Trans. IMF 1950, 27, 153-169. [CrossRef]

51. Chen, J.; Li, J.; Xiong, D.; He, Y.; Ji, Y.; Qin, Y. Preparation and tribological behavior of Ni-graphene composite coating under room temperature. Appl. Surf. Sci. 2016, 361, 49-56. [CrossRef]

52. Hu, C.; Wang, C. Effects of composition and reflowing on the corrosion behavior of Sn-Zn deposits in brine media. Electrochim. Acta 2006, 51, 4125-4134. [CrossRef]

53. Osório, W.; Spinelli, J.; Afonso, C.; Peixoto, L.; Garcia, A. Microstructure, corrosion behaviour and microhardness of a directionally solidified Sn-Cu solder alloy. Electrochim. Acta 2011, 56, 8891-8899. [CrossRef]

54. Zheng, D.; Li, M.; Li, Y.; Qin, C.; Wang, Y.; Wang, Z. A Ni(OH $)_{2}$ nanopetals network for high-performance supercapacitors synthesized by immersing Ni nanofoam in water. Beilstein J. Nanotechnol. 2019, 10, 281-293. [CrossRef]

Publisher's Note: MDPI stays neutral with regard to jurisdictional claims in published maps and institutional affiliations.

(C) 2020 by the authors. Licensee MDPI, Basel, Switzerland. This article is an open access article distributed under the terms and conditions of the Creative Commons Attribution (CC BY) license (http://creativecommons.org/licenses/by/4.0/). 